\title{
MicroRNAs in Animal Models of HCC
}

\author{
Francesca Fornari ${ }^{1,2, *}$, , Laura Gramantieri ${ }^{1, *}$, Elisa Callegari ${ }^{3}$, Ram C. Shankaraiah ${ }^{3} \mathbb{C}$, \\ Fabio Piscaglia ${ }^{1,2}$, Massimo Negrini ${ }^{3}$ and Catia Giovannini ${ }^{1,2}$ (D) \\ 1 Center for Applied Biomedical Research, St. Orsola-Malpighi University Hospital, 40138 Bologna, Italy; \\ fabio.piscaglia@unibo.it (F.P.); catia.giovannini4@unibo.it (C.G.) \\ 2 Department of Medical and Surgical Sciences, University of Bologna, 40138 Bologna, Italy \\ 3 Department of Morphology, Surgery and Experimental Medicine, University of Ferrara, 44121 Bologna, Italy; \\ elisa.callegari@unife.it (E.C.); shnrch@unife.it (R.C.S.); massimo.negrini@unife.it (M.N.) \\ * Correspondence: francesca.fornari2@unibo.it (F.F.); laura.gramantieri@aosp.bo.it (L.G.); \\ Tel.: +39-0512-143-902 (F.F.)
}

Received: 4 November 2019; Accepted: 28 November 2019; Published: 1 December 2019

\begin{abstract}
Hepatocellular carcinoma (HCC) is the second leading cause of cancer-related mortality. Molecular heterogeneity and absence of biomarkers for patient allocation to the best therapeutic option contribute to poor prognosis of advanced stages. Aberrant microRNA (miRNA) expression is associated with HCC development and progression and influences drug resistance. Therefore, miRNAs have been assayed as putative biomarkers and therapeutic targets. miRNA-based therapeutic approaches demonstrated safety profiles and antitumor efficacy in HCC animal models; nevertheless, caution should be used when transferring preclinical findings to the clinics, due to possible molecular inconsistency between animal models and the heterogeneous pattern of the human disease. In this context, models with defined genetic and molecular backgrounds might help to identify novel therapeutic options for specific HCC subgroups. In this review, we describe rodent models of HCC, emphasizing their representativeness with the human pathology and their usefulness as preclinical tools for assessing miRNA-based therapeutic strategies.
\end{abstract}

Keywords: HCC; microRNA; animal models

\section{MicroRNAs in HCC}

MicroRNA (miRNA) profiles are highly informative for tumor classification and prognosis [1,2]. In line, the aberrant expression of miRNAs represents a hallmark of human hepatocellular carcinoma (HCC); miRNAs signatures associated with increased HCC risk, neoplastic development, advanced stages, and vascular invasion, were identified in human HCC, and some of them were confirmed in rodent models and tested as therapeutic targets [3-8] (Figure 1). From a mechanistic perspective, functional studies have demonstrated the active involvement of specific miRNAs in the regulation of key pathways driving hepatocarcinogenesis, through the direct targeting of crucial oncogenes or tumor-suppressor genes [3,9-14]. Besides a restricted panel of informative miRNAs shared by different cohorts, a remarkable inconsistency can be observed across independent studies. This inconsistency may be ascribed to the heterogeneous prevalence of etiologies, environmental and genetic factors, and technical and analytical reasons. The molecular heterogeneity of HCC indeed still represents a critical factor. A lack of biomarkers classifying HCC subgroups still limits our ability to allocate patients to the best therapeutic option. In this perspective, identifying common molecular traits shared by specific HCC subgroups and animal models might help to deepen molecular knowledge, favoring the discovery of novel diagnostic and therapeutic approaches in molecularly defined contexts. Due to the putative roles of miRNAs as molecular biomarkers (both tissue and circulating) as well as therapeutic targets or therapeutic molecules, this class of RNAs deserves attention as a useful tool at multiple levels. 


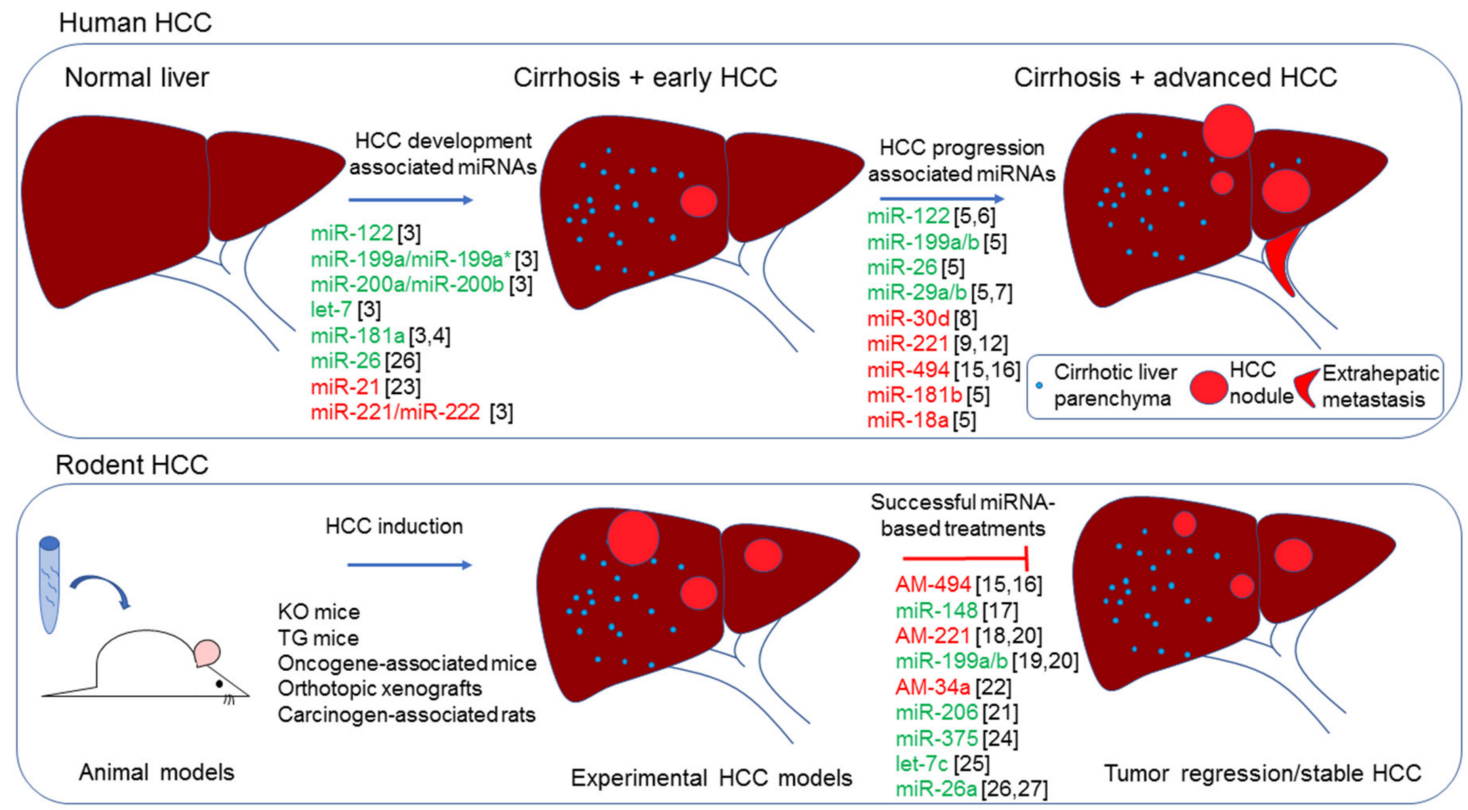

Figure 1. miRNA deregulated in human and rodent human hepatocellular carcinomas (HCCs) and miRNA-based approaches in preclinical models. Top panel depicts miRNA involved in human hepatocarcinogenesis from early development to advanced stages. Downregulated miRNAs are in green; upregulated miRNAs are in red. Bottom panel depicts experimental animal models of HCC and successful miRNA treatments reducing tumor burden. miRNA mimics treatments are in green; anti-miRNA (AM) treatments are in red [3-9,12,15-27].

\section{Animal Models and HCC Research}

More than $80 \%$ of human HCCs arise in a field of chronic liver disease resulting from viral hepatitis, alcohol abuse, metabolic syndrome, exposure to carcinogenic agents, and genetic diseases such as Wilson's disease or hemochromatosis. Different etiologies, together with different ethnicities, contribute to the high HCC heterogeneity. Since molecular inter-tumor and intra-tumor heterogeneity is a matter of fact in HCC [28], identifying subclasses with predictable prognosis and response to treatments is one of the major challenges in the clinical management of this disease. The development of animal models that recapitulate in vivo the multistep natural history of HCCs might help in understanding the causes, as well as provide the rationale for testing treatments. The "ideal" animal model should mimic human HCC natural history. However, no model is "ideal" for all HCC research purposes, and spontaneous models of tumorigenesis are rare. Because of the genetic similarities between rodents and humans, the breeding capacity, and the short lifespan, rodents are widely used for cancer research. A wide range of models is currently available to study HCC development and therapeutic treatments, including chemically induced, transgenic, or knockout mice; xenograft mice; and dietary-induced models, such as the choline-deficient diet. In addition, combinations of different models have also been used. Beside mice and rats, zebrafish (Danio rerio) also deserve attention due to a series of characteristics that will be briefly described. Since there is no single dominant molecular driver underlying all HCCs, specific models should be chosen according to their representativity of specific subtypes of HCCs. Genomic and transcriptomic studies classify HCC based on molecular pathway activation. Comparison of gene expression between each animal model and human HCC subgroups may help to choose the ideal model for specific aims. Here, we review some of the most representative HCC animal models selected on the basis of the following:

- $\quad$ The extent of representativeness and the relevance of miRNA deregulation in human HCC;

- $\quad$ The translational relevance of miRNA-based therapeutic intervention in rodent models. 


\section{3. miRNAs Knockout and Transgenic Mice}

The development of genetically engineered mouse (GEM) models greatly contributed to the advancement of knowledge of pathogenic mechanisms sustaining human diseases, including cancer. The great advantage of GEM is that genetic manipulations can be introduced systematically, in a specific organ, but also at defined time points during development, growth, and aging. An exhaustive description of conditional and inducible expression systems has been reviewed by He and coworkers [29]. GEM models also provide an optimal background for preclinical studies testing molecularly based treatments. miRNA-based knockout (KO) or transgenic (TG) models will be hereafter briefly described.

\section{KO Mouse Models}

\subsection{Dicer1 KO Mouse Model}

To investigate the consequences of miRNA disruption in liver physiology, Dicer 1 conditional knockout mice were established and showed initial preservation of liver function, followed by the development of progressive liver dysfunctions leading to prominent steatosis, lipid, and glucose metabolism impairment, increased hepatocyte proliferation, and, finally, onset of HCC [30,31]. These studies reported the downregulation of the hepatospecific miR-122 that accounts for $70 \%$ of all expressed miRNAs in normal liver, which role in cholesterol biosynthesis and lipid metabolism is well established [32,33]. Interestingly, despite liver repopulation by Dicer positive cells at 12-month after birth, two-third of Alb-Cre; Dicer (flfll) animals displayed liver tumors exhibiting decreased levels of Dicer 1 and lack of miR-122 expression with respect to non-neoplastic surrounding tissue, demonstrating the loss of dicer as a driver event in hepatocarcinogenesis [30]. In line, the downregulation of miRNA machinery components (Dicer1 and p68) is a frequent event in HCC and it is associated with decreased tumor-free survival [34].

\section{2. miR-122 KO Mouse Model}

Several lines of evidence highlight the importance of miR-122 in liver biology and disease, as suggested by its downregulation in most of HCC tissues and its peculiar role in noncanonical regulation of hepatitis $\mathrm{C}$ virus (HCV) life cycle, as well as by the modulation of genes involved in the maintenance of the adult liver phenotype [3,32,35]. In this scenario, germline and liver-specific conditional miR-122-KO mice were developed in order to investigate the consequences of its genetic loss [36,37]. Both miR-122-KO and liver-specific KO (LKO) mice developed microsteatosis and liver inflammation, characterized by increased lipid droplets and infiltrating cells secreting inflammatory cytokines (IL- 6 and TNF- $\alpha$ ), that progressed to steatohepatitis, fibrosis and spontaneous HCC. Notably, an enrichment of transcripts bearing a miR-122 complementary binding site in their 3'UTR was detected in LKO mice and ingenuity pathway analysis (IPA) revealed the altered expression of genes belonging to triglyceride biosynthesis, as well as oncogenes, commonly associated with malignant transformation, such as insulin-like growth factor 2 (Igf2), beta catenin (Ctnnb1), Kirsten rat sarcoma viral oncogene homolog (Ras), epithelial cell adhesion molecule (Epcam), and avian myelocytomatosis virus oncogene cellular homolog (c-Myc). In addition, a signature of genes specifically deregulated in miR-122-KO and LKO mice was able to stratify human tumor samples into high or low miR-122 expression groups, suggesting these preclinical models as representative of the human pathology, mimicking key features of cancer progression in a background of fatty liver disease [36]. Similarly, the reactivation of embryo-specific genes and imprinted miRNA clusters was reported following adeno-associated virus (AAV)-mediated miR-122 transient disruption in a mouse model. In particular, several miRNAs located in Igf2 and Dlk1-Dio3 imprinted loci were markedly activated following miR-122 loss in liver tissue from both transient and stable miR-122-KO mice, suggesting initiation of precancerous transcriptional modifications in mice lacking miR-122 expression [38,39]. These studies emphasize the intriguing idea of complex regulatory networks and inter-relationships between miRNAs, transcription factors, 
epigenetic modulators and miRNA machinery complexes whose stringent cooperation defines the precancerous transcriptional phenotype observed in miR-122-/- mice that is, strikingly, shared by human HCCs.

Notably, in vivo gene targeting of Dlk1-Dio3 locus by AAV vectors causing its overexpression led to HCC development in $100 \%$ of mice and, in line, overexpression of this miRNA cluster associated with an aggressive stem-cell-like phenotype in HCC [40]. Others and our group reported the upregulation of miR-494, a member of the Dlk1-Dio3 miRNA cluster, in 25-30\% of HCCs with stemness features and demonstrated its involvement in tumor progression and sorafenib resistance through the direct targeting of mutated in colorectal cancer $(M C C)$ and the phosphatase and tensin homolog (PTEN) tumor suppressor gene [15,16]. Regarding IGF2/483 oncogenic locus, an increase of miR-483-3p was found in 30\% of human HCCs and Bcl-2 binding component 3 (BBC3/PUMA), a Bcl-2 family member with pro-apoptotic functions, was identified among its target genes, suggesting miR-122 KO models as representative of a subgroup of HCCs with stem-cell-like characteristics and epigenetic deregulation [41].

\section{3. miR-148a KO Mouse Model and Epigenetic Changes}

Knockout mice for miR-148a, a liver abundant miRNA, were established to assess its intrinsic role in liver physiology and to characterize its contribution to hepatocarcinogenesis. Indeed, miR-148a-3p/5p decreased expression was observed in tumor versus nontumor tissue of HCC patients, and it was associated with poor differentiation and reduced overall survival. miR-148a-KO mice showed an increase of steatosis and serum total cholesterol levels, as well as an upregulation of genes involved in lipogenesis and fatty acid uptake, when fed with both a regular-chow diet (RCD) and high-fat diet (HFD). As expected, several genes involved in lipid and cholesterol biosynthesis were identified among miR-148a-3p/5p targets displaying increased levels in KO animals, independently of the diet. Moreover, tumor induction by a single diethylnitrosamine (DEN) injection led to an increased number and size of tumor nodules in $\mathrm{KO}$ mice, whereas restoring pri-miR-148a levels reduced tumor count and volume [17]. Interestingly, miR-148a progressive upregulation was detected in a mouse fetal hepatoblast model when subjected to liver differentiation, which corresponded to an opposite decrease of its target gene DNA methyltransferase 1 (DNMT1). Functional analysis demonstrated the involvement of miR-148a/DNMT1 axis in triggering expression of adult hepatic markers, albumin (Alb), glucose-6-phosphatase catalytic subunit (G6PC), and tyrosine aminotransferase (Tat), and proved a negative feedback loop between miR-148a and DNMT1 itself. Notably, miR-148a decreased expression was detected in liver biopsies from HCC patients with respect to normal livers, but not surrounding tissues, suggesting its involvement in the progression of the underlying liver disease. Finally, gain-and-loss of function studies demonstrated its role in preventing invasive capabilities of HCC cells through mesenchymal epithelial transition factor (c-Met) indirect targeting and reported the oncogene c-Myc among miR-148a transcriptional inhibitors contributing to its downregulation during hepatocarcinogenesis [42].

\section{4. miR-223 KO Mouse and NAFLD}

A recent study described the protective activity of the neutrophil-associated miRNA, miR-223, in nonalcoholic steatohepatitis (NASH) and HCC, by the direct targeting of inflammatory and oncogenic genes upregulated in these pathologic conditions. HFD-fed C57BL/6J mice developed steatosis but were resistant toward NASH progression; strikingly, higher tissue levels of the anti-inflammatory miR-223 were found in hepatocytes from HFD-fed mice, as well as in liver specimens from NASH patients, with respect to control-diet-fed animals and healthy liver samples, respectively. miR-223KO mice developed a full spectrum of nonalcoholic fatty liver disease (NAFLD) and more severe NASH phenotypes, as corroborated by higher levels of serum alanine aminotransferase (ALT), greater liver infiltration and fibrosis, and increased mRNA levels of pro-inflammatory cytokines. In addition, IPA of microarray data revealed the dysregulation of genes contributing to carcinogenesis and inflammatory response 
in KO with respect to wild type (WT) mice after three months of HFD. In line, half of miR-223KO animals developed HCC after long-term HFD feeding, showing an increased susceptibility to disease progression. Since miR-223 positively correlated with several chemokines (C-X-C motif chemokine 10, CXCL10) and cytokines (interleukin-6, IL-6) and with cancer-related genes (glypican 3, GPC3) in NASH patients, the authors hypothesized a protective role for miR-223 against malignant transformation and disease progression, contributing to the explanation as to why HFD feeding alone is not sufficient for NAFLD progression in mouse models [43]. These interesting findings depicting the anti-inflammatory role of miR-223 in NASH patients agree with data from other groups, as wee as our own, showing a downregulation of miR-223 in HCC with respect to surrounding nontumor tissues from surgically resected HCCs, corroborating the idea that high miR-223 levels restrain tumor development $[3,44]$.

\section{Transgenic Mouse Models}

\section{1. miR-221 TG Mouse}

miR-221 is upregulated in $70-80 \%$ of HCCs and in a wide range of different malignancies. The recognition of miR-221 related targets, such as the cyclin-dependent kinase inhibitors CDKN1B/p27 and CDKN1C/p57, PTEN, or the pro-apoptotic protein Bcl2 modifying factor (BMF), explains several mechanisms through which its upregulation contributes to carcinogenesis $[9,10,14]$. We developed a liver-specific miR-221 transgenic mouse model (TG221) which spontaneously develops HCC in $50 \%$ of male mice aged 9-12 months. DEN administration accelerates the appearance of liver cancer that becomes visible at 3-4 months of age in all male mice. Interestingly, in this TG model, the degree of miR-221 upregulation quantitatively matches the extent of miR-221 deregulation in human HCC, with a two-to three-fold change when comparing HCC with surrounding tissue. Specifically, following intraperitoneal DEN injection TG221 animals displayed a higher liver weight associated with increased number and volume of tumor nodules [18]. Lower expression of miR-221 validated targets, p27, p57, and Bmf in TG tumors and liver samples with respect to WT animals confirmed this model as representative of molecular mechanisms previously identified in HCC cell lines and human tumors [10]. This model was employed to test in vivo the antitumor activity of chemically modified anti-miR oligonucleotides (AMOs). Briefly, the experimental protocol consisted in one intraperitoneal (IP) injection of DEN in 10-day newborn TG mice and, two months later, three intravenous (IV) injections of anti-miR-221 every 15 days. A reduction of size and number of tumors was detected in the group receiving miR-221 AMOs with respect to control-treated mice, showing a persistent decrease of miR-221 levels and demonstrating the specificity and efficacy of this therapeutic strategy. Therefore, the TG221 model confirmed miR-221 as a driver gene for HCC development and progression and resulted as an effective tool to test miRNA-mimic or anti-miRNA-based approaches increasing the knowledge regarding their safety, specificity, and efficacy for the treatment of HCC. In this regard, the expression of several HCC-specific miRNAs, miR-199a-3p, miR-122, and miR-21 in TG221 mice reflected those observed in primary human HCCs; therefore, this model was employed to assay the anticancer activity of miRNA mimic oligonucleotides too [18]. Besides anti-miR-221, miR-199a/b-3p mimics were tested to treat HCCs developed in miR-221 TG mouse. miR-199a-3p represents the third most abundantly expressed miRNA in the liver, and it is downregulated in virtually all HCCs with a fold change greater than 10-fold in many cases, representing an ideal candidate for in vivo replacement therapy [3,45-47]. It controls several cancer-associated genes, such as mammalian target of rapamycin $(m T O R)$, hepatocyte growth factor receptor $c-M e t$, the kinase p21-activated kinase 4 (PAK4), and the Notch regulator Yes-associated protein 1 (YAP1). Since an miR-221 TG mouse also displays miR-199a-3p constitutive downregulation, miR-199a-3p mimics were adopted by using two experimental protocols: DEN priming in 10-day newborn mice followed by three IP injections per week for three weeks at three or five months of age. Both protocols showed a decreased number and size of nodules in miR-199a-3p mimics treated group with an anticancer effect similar to that observed in sorafenib-treated mice [19]. A decrease of mTOR and PAK4 protein expression was observed in HCC 
specimens from miRNA mimics treated animals, confirming similar mechanisms of action observed in other preclinical models, as well as in human HCCs $[3,46]$. An interesting finding is that the livers of miR-221 TG mice are characterized by a relevant steatohepatitis, which resembles the human NASH that is becoming a more and more prevalent risk factor for HCC [48].

\section{2. miR-221 TG Mouse Developing HCC on Liver Cirrhosis}

One limitation of most HCC murine models is the absence of cirrhosis, which, instead, accompanies the multistep natural history of human HCC in about $90 \%$ of cases, with the well-known role of associated microenvironmental changes. Genetic manipulations may modify the expression of key molecules driving liver carcinogenesis allowing studying specific mechanisms, which, however, take place on a healthy liver. The preneoplastic stage of cirrhosis represents a background to be kept in mind when trying to match animal models with human disease. Indeed, cirrhosis is a distinct disease to face with and its own contribution through microenvironmental changes should be considered when assaying novel biomarkers or dissecting molecular mechanisms. This is true not only for molecular purposes, but also for functional reasons when testing the therapeutic/toxic effect of drugs. Notwithstanding this, the animal models of HCC arisen on a background of overt cirrhosis are very few. Among these, the HCC mouse model developed by Domenicali and co-authors provides the background for repeated cycles of liver damage/regeneration to reflect faithfully the events leading to the development of cirrhosis [49] This model recapitulates the progression from hepatocyte cell death, proliferation, fibrosis, towards cirrhosis with portal hypertension syndrome. Notably, only a very restricted fraction of these animals develops HCC. Briefly, a well-tolerated protocol able to induce cirrhosis in C57BL/6N mice consisted of administration of the carbon tetrachloride (CCl4) by short inhalation cycles, twice or three times weekly, administered through increasing exposure times, resulting in a safe and effective method to induce decompensated cirrhosis with ascites. Conversely, subcutaneous or intraperitoneal $\mathrm{CCl} 4$ administration displayed adverse events, preventing the development of an overt cirrhosis with portal hypertension syndrome. Thus, Callegari et al. applied this model in mice bearing a genetic factor that predisposed them to HCC, such as the miR-221 TG mouse [18]. Taking advantage of the protocol developed by Domenicali et al. [49], multiple short-term inhalation cycles of CCl4 were used to induce decompensated cirrhosis in TG221 transgenic mice, to test the possibility of inducing liver tumors in the context of cirrhosis. Unlike the very low incidence of HCC in control mice developing cirrhosis, when applied to TG221 mice at four weeks from the end of $\mathrm{CCl} 4$ treatment, ultrasound analysis revealed large liver nodules which were histopathologically confirmed as dysplastic nodules or HCC, whereas, in WT mice, most were macro-regenerative or hyperplastic nodules, without dysplastic features. All animals displayed overt cirrhosis, demonstrated by histopathological examination, by the presence of ascites, and by activation of fibrotic markers such $\alpha$-smooth muscle actin $(\alpha-S M A)$, connective tissue growth factor (CTGF), and transforming growth factor beta 1 (TGF-1). Notably, in TG221 mice, necro-inflammatory changes were more intense and extended, and progression to dysplastic nodules or HCCs was confirmed based on morphology, immunohistochemistry (increased expression of tumor-associated genes such as alpha-fetoprotein ' $A F P^{\prime}$ and ' $G P C 3$ ') and gene expression patterns. This model appears to recreate faithfully the natural history of HCC on a background of cirrhosis. It could also be considered to investigate microenvironmental changes associated with disease progression and to achieve functional implications relevant for drug metabolism and toxicity. In conclusion, the cirrhosis-associated TG221 model represents a robust preclinical tool for testing therapeutic or prophylactic strategies in a preclinical setting recapitulating the pathophysiology of human HCC [20].

\section{3. miR-17-92 TG Mouse}

miR-17-92, together with its paralogous miR-25-106b cluster, is one of the first polycistronic miRNA clusters whose overexpression was recognized in hematologic and solid tumors [50,51]. miR-17-92 is transcriptionally regulated by c-Myc proto-oncogene, and it is required to maintain a 
neoplastic state through the regulation of genes involved in chromatin remodeling and apoptosis [52,53]. In order to dissect the contribution of miR-17-92 cluster to hepatocarcinogenesis, Zhu and coworkers investigated its expression in HCC patients and established a transgenic mouse model overexpressing the six-miRNA family members in the liver. Quantitative polymerase chain reaction (QPCR) analysis and in situ hybridization (ISH) were performed in two HCC patient cohorts reporting miRNA (miR-17, miR-18, miR-19a, miR-19b, miR-20, and miR-92) overexpression in tumor tissues with respect to nontumor specimens; miRNA sequencing data from the Cancer Genome Atlas (TCGA) database further confirmed their overexpression in a larger cohort of patients. The miR-17-92 TG mouse model showed augmented propensity to liver cancer induction following DEN administration in comparison to WT mice, as evidenced by an increase of tumor nodule number and volume at 10 -month. In addition, TG mice displayed a faster tumor progression, showing a higher percentage of HCC nodules [54].

\subsection{HBx Transgenic Mouse and miR-224}

An intriguing mechanism of miRNA degradation was proposed for miR-224 whose expression negatively correlated with autophagy in HBV-related HCCs, as demonstrated by the tissue array of autophagy-associated markers (autophagy related 5 'Atg5', Beclin1, and p62) and ISH for miRNA detection in a cohort of 93 HCC patients. In particular, a negative correlation between miR-224 and autophagy-promoter gene Atg5, and a positive correlation between miRNA levels and p62 gene, whose accumulation typically characterizes autophagy impairment, were displayed in hepatitis B virus (HBV)-infected patients, but not in hepatitis $\mathrm{C}$ virus (HCV)-positive ones. To confirm this peculiar miR-224/autophagy relationship occurring in HBV-related HCCs and to clarify autophagy-mediated mechanisms of miRNA regulation, an Hepatitis B Virus protein $X$ (HBx) transgenic mouse model was used [55]. The oncogenic properties of the HBx gene are indeed well-known and these TG animals, established in 1991, showed progressive histopathological liver changes progressing to carcinomas that were fatal to all the animals [56]; thus, they represent ideal models for defining molecular events involved in HBV-associated liver tumorigenesis. Low Atg5 expression accompanied by p62 accumulation and high miR-224 levels were detected in tumor specimens with respect to nontumor tissues of 17.5 months old mice. Notably, only mature miR-224 isoform but not precursor transcript was upregulated in HCC patients and HBx TG mice, suggesting post-transcriptional events participating to its regulation. Elegant in vitro experiments with autophagy inducers and inhibitors demonstrated miR-224 recruitment to the autophagosome and its degradation following fusion with lysosomes, independently from viral status of hepatoma cells, postulating that induction of autophagy or miR-224 antagonism are effective antitumor strategies in HCC. In addition, SMAD family member 4 (Smad4) and glycine-N-methyltransferase (GNMT) were described among miR-224 target genes, and their involvement in liver injury and tumor progression was proved by in vitro and in vivo models [55,57]. Again, miR-224 upregulation and inverse correlation with its target GNMT were described in HBV-related HCC patients only, confirming the virus-specificity for miR-224 aberrant expression [55,57]. Consistently, miR-224 upregulation characterized early stages of HBV-related hepatocarcinogenesis in different animal models, highlighting the necessity of proper animal models when virus-related miRNA-based therapeutic options are concerned [58].

Interestingly, Tang and coworkers compared gene-expression profiling between HBX-TG mice and chemically induced DEN-HCC mice. They showed that upregulated genes in tumor versus normal tissue were mainly involved in immune and acute-phase response and cholesterol and lipid biosynthesis in the DEN model, whereas upregulated genes belonged to positive regulation of gene expression, cell proliferation, migration and invasion, and immune response in the HBX model. On the contrary, both models shared common deregulated genes involved in metabolic pathways and redox processes. Moreover, early growth response 1 'Egr1', activating transcription factor 3 'Atf3' and Kruppel-like factor 4 'Klf4' resulted as the main regulatory factors in HBX mice controlling cancer-associated signaling pathways, such as PI3K/AKT, MAPK, Ras, and p53, which role in hepatocarcinogenesis is well established [59]. Notably, several oncogenes and tumor-suppressor (TS) genes deregulated in 
human HCC were controlled by these transcription factors, highlighting the reliability of the HBX mouse model with respect to the human pathology.

\section{Oncogene-Related TG Mice}

Myc and Ras are canonical oncogenes whose increased expression, amplification, or pathway activation has been identified in most of human cancers. Regarding HCC, Ras pathway is often activated due to promoter hypermethylation of Ras association domain family member 1 (RASSF1) and novel Ras effector 1A (NORE1A) inhibitors [60]. Interestingly, MYC oncogene was recently associated with a gene regulatory network formed by lin-28 homolog B (LIN28B), CTNNB1, SWI/SNF Related, Matrix Associated, Actin Dependent Regulator of Chromatin, Subfamily A, Member 4 (SMARCA4), Let-7b, SRY-Box Transcription Factor 9 (SOX9), and TP53 that correlated with increased proliferation, dedifferentiation and c-Met pathway activation more likely contributing to the transcriptional signature typical of the HCC "proliferation" subclass [61].

Oncogene-inducible liver-specific transgenic mouse model gave rise to liver tumors with a $100 \%$ penetrance within 12 weeks. Histological characterization revealed that Myc-driven tumors resemble poorly differentiated HCCs or human hepatoblastomas, Ras-driven tumors resemble human HCCs, and $M y c+$ Ras-driven tumors mirrored an aggressive variant of HCC or fetal variant of hepatoblastoma. Molecular characterization showed the overexpression of chromosome 12qF1 miRNA megacluster, comprising 53 miRNAs, in Myc, Ras, and Myc + Ras TG mice and in a subgroup of human HCCs (human homolog located at chromosome locus 14q32). In particular, a 60-miRNA signature was shared by these three oncogene-dependent models and was representative of an HCC patients' subgroup with high AFP expression, displaying 29 out of 60 members belonging to the Dlk1-Dio3 miRNA cluster. Since miR-494 showed the highest activity in a colony forming unit assay and increased cell cycle progression through MCC targeting, the antitumor potential of miR-494 antagonist molecules was tested in Myc-driven HCC bearing mice showing decreased tumor burden associated with increased p27 and MCC protein levels [16]. In line, we demonstrated p27 as a miR-494 direct target gene in HCC cell lines and xenograft mice playing a role in cell cycle fastening and cell proliferation in miR-494 overexpressing Huh-7 cells, suggesting that both animal models might be suitable for identification of miR-494 downstream molecular mechanisms [15]. Similarly, miR-206 was commonly downregulated among $c-M y c$ and AKT/Ras-oncogene induced HCC mouse models, HCC cell lines, and human HCCs contributing to tumor development and progression through cell cycle regulator cyclin D1 (CCND1), c-MET, and cyclin-dependent kinase 6 (CDK6) direct targeting, as demonstrated by in vitro and in vivo experiments [21]. Notably, oncogene overexpression might be obtained not only through the establishment of TG mice but, more easily, through hydrodynamic tail-vein injection, which is an efficient procedure to deliver nucleic acids, primarily to the liver, taking advantage of its peculiar fenestrated sinusoids. By means of a rapid injection of a large liquid volume containing the specific sequences of interest, mouse models with stable gene expression can be generated. Strikingly, miR-206 hydrodynamic delivery in concomitance with $c-M y c$ and AKT/Ras oncogenes prevented tumor formation and cancer-associated death of all animals, emphasizing the suppressor role for miR-206 in HCC initiation in both oncogene-derived mouse models.

In conclusion, genetically engineered models represent optimal tools for investigating miRNA involvement in hepatocarcinogenesis (Dicer1KO, miR-122KO), for testing anticancer activity of miRNA-based therapeutic option (TG221 + DEN; HBx TG; oncogene-related TG mice) and for recreating the multi-step pathogenic history of HCC development in a cirrhotic (TG221 + CC14) or metabolic (miR-223KO) background.

\section{HCC Mouse Models and miRNA-Based Therapeutic Approaches}

A growing body of evidence support the involvement of miRNAs in the coordination of complex cellular programs, due to their ability to regulate hundreds or thousands of targets. Since the liver represents an ideal organ for gene therapy, first in vivo studies demonstrated the nontoxicity and 
efficacy of chemically modified oligonucleotides targeting the liver-specific miR-122 in both rodent and nonhuman primate species [32,62]. Regarding miRNA-based therapeutic strategies, several pros and cons have to be considered when clinical trials are concerned. Indeed, on the one hand, the intrinsic nature of miRNAs as multi-regulators of gene expression represents an advantage for cancer treatment favoring the targeting of multiple steps of a single pathway, as well as contemporaneous inhibition of redundant pathways that could represent tumor escape mechanisms associated with drug-resistant phenotypes. On the other hand, this multitargeting ability might trigger opposite effects, depending on tissue of origin, but also on cellular context within a single tumor, where the same miRNA might behave as a tumor-suppressor gene or as an oncogene, depending on constitutive expression of targets [63]. As an example, we reported the dual role for oncomiR-221 in cell proliferation and drug sensitization based on p53 status, as well as the simultaneous targeting of PTEN tumor-suppressor gene and AKT3 oncogene, both belonging to the AKT/mTOR pathway, by miR-519d, which is strongly upregulated in $50 \%$ of HCCs $[64,65]$. These apparent contradictory functions of miRNAs can be understood when we consider their physiologic activities and their prominent role that is the fine-tuning of cellular processes, balancing complex molecular networks at multiple levels. Of note, this equilibrium might be no more applicable to diseased states such as cancer. Even more importantly, this concept should be considered when we hypothesize to use miRNAs as therapeutic molecules. In this regard, it is mandatory to identify those molecular settings in which miRNA manipulation targets specific driver mechanisms. In the abovementioned case of miR-519d, which targets both PTEN and AKT3, its inhibition in HCCs with high PTEN expression is able to counteract AKT/mTOR pathway. Conversely, in HCC with PTEN null expression, it would determine an even stronger AKT/mTOR pathway activation through AKT3 upregulation, contributing to tumor cell proliferation and invasion.

Due to the frequent downregulation of miR-34a in most of human tumors, including HCC, the first clinical trial testing of a liposomal miR-34a mimics-based formulation is now ongoing in oncologic patients at advanced stages [66]. Notably, Gougelet and colleagues described the overexpression of miR-34a in HBV-related HCCs and APC ${ }^{-/-}$transgenic mice where its silencing by means of locked nucleic acid (LNA) probes slowed down tumor progression, emphasizing the need for delineation of accurate patients' subclasses based on their molecular patterns when miRNA-mediate approaches are concerned [22]. In this scenario, miRNAs represent optimal target genes and attractive candidates for single or combined therapeutic strategies. In the abovementioned oncogene-related mouse model injected with $A K T / R a s$ or $c-M y c$ to induce HCC, the therapeutic potential of two different miR-206-based molecules was assayed. The first strategy was based on minicircle episomal DNA vectors, which have a smaller size that enables more efficient delivery and sustained expression in a period of weeks with respect to greater DNA plasmid vectors. The second strategy considered miRNA mimics modified at 2'O-methyl and labeled with four cholesterol groups, to increase the stability and transfection efficiency. Both strategies showed a marked anticancer effect in $c-M y c$ mice, decreasing tumor growth and target genes expression, but failed to repress tumor growth of $A K T / R a s$ mice, perhaps due to their more rapid growth, underlining the importance to test miRNA-based therapeutics in different animal models and suggesting again the need for patient stratification based on genomic and transcriptomic backgrounds [21]. In the following paragraphs, we describe miRNA-based antitumor approaches in xenograft and orthotopic HCC mouse models, focusing on their representativeness of human pathology and translation into the clinics (Figure 1).

\section{Xenograft Mice}

Xenograft models are obtained by subcutaneous injection of tumor cells into immunocompromised mice and have been largely used in preclinical studies due to their easy manipulation. They represent a good tool for a rapid in vivo screening of tumor growth and drug response, even though caution has to be used when translating results into the clinical practice. Indeed, major disadvantages with respect to GEM are (1) the absence of a proper immune response by the host and (2) the lack of an appropriate tumor microenvironment. On the other hand, the advantage of xenograft with respect 
to GEM models is represented by their easy and rapid establishment, as well as by the employment of human cells that might better reflect human tumor phenotypes and drug response with respect to mouse tumors. The ability of cancer cells to develop a multidrug resistant phenotype represents a major obstacle for both standard chemotherapy and molecular targeted therapy leading to treatment failure and tumor progression and limiting effective chances to cure oncologic patients. The presence of redundant molecular mechanisms favors tumor escape, and targeting single molecules often activates compensatory pathways allowing survival of neoplastic/progenitor cells. Since pharmacologic treatments modify a conspicuous number of signaling cascades, the miRNA-based multiple inhibition of regulatory elements combined with clinically available drugs might be a successful strategy in the field of molecular oncology. Regarding HCC, an interesting study by Tang and coworkers described the antiproliferative effect of an artificial long noncoding RNA (AlncRNA) simultaneously targeting six miRNAs whose expression is upregulated during sorafenib treatment, namely miR-21, miR-153, miR-216a, miR-217, miR-494, and miR-10a-5p. Interestingly, PTEN is a common and validated target of all these miRNAs, as well as the principal negative regulator of the pro-survival AKT/mTOR pathway, whose activation represents an unfavorable event often occurring in sorafenib-acquired resistance and promoting cell proliferation and autophagy blockage [67]. Intratumoral injection of adenoviral particles Ad5-AlncRNA in a sorafenib-resistant xenograft mouse model induced only a slight decrease of tumor growth but strongly synergized sorafenib antitumor activity, half-reducing tumor weight, decreasing Ki-67 staining, and increasing terminal deoxynucleotidyl transferase dUTP nick end labeling (TUNEL)-positive cells with respect to control animals [68]. In agreement, in our experience, the only overexpression of miR-494 in HCC xenografts does not impact on tumor growth, whereas in the setting of sorafenib treatment, overexpression of miR-494 determines resistance, suggesting the central role for miR-494/PTEN/AKT/mTOR/p27 axis in sorafenib sensitization in HCC [15]. He and coworkers described similar findings reporting the synergistic effect of anti-miR-21 oligonucleotides coupled with sorafenib in a xenograft model obtained by subcutaneous inoculation of sorafenib resistant Huh-7 cells. In particular, miR-21 silencing in vivo restored sorafenib sensitization through PTEN targeting and autophagy activation as assessed by Ki-67 and TUNEL staining as well as by transmission electron microscopy showing a consistent increase of apoptotic cell death and autophagosome vesicles [23].

In the last years, several efforts were made toward the development of efficient nanotherapeutics for the delivery of miRNA-based oligonucleotides, increasing organ-specific targeting and reducing miRNA degradation by systemic endonucleases. Interestingly, a recent study developed a straightforward strategy to deliver miR-375 in HCC cells in both in vitro and in vivo studies assembling miRNA mimics molecules on the surface of gold nanoparticles (AuNP). Several properties make these oligonucleotide-functionalized nanoparticles ideal for biomedical applications, such as their ability to be captured and internalized by cultured cells or animal tissue without the aid of other carriers, the increased nuclease resistance of coated miRNAs and a lower activation of host immune response. Intratumoral injection of miR-375 nanoparticle formulation markedly reduced tumor growth of HepG2 xenograft masses. These findings were confirmed in a second HCC mouse model obtained by hydrodynamic injection of $A K T / R$ as oncogenes and tail-vein administration of AuNP-miR-375 showing a consistent increase of apoptotic markers and a reduction of tumor nodules and hepatocyte proliferation [24].

Several considerations arise from studies on xenograft models: (i) the contemporaneous modulation of different miRNAs targeting common pathways might help control tumor recurrence and drug-resistant phenotypes (lnRNA-mediated approaches); (ii) the combination of miRNAs and chemotherapeutics or targeted molecules might potentiate drug efficacy (miR-494 and miR-21 combined with sorafenib); (iii) the development of delivery systems favors optimal miRNA uptake by cancer cells.

\section{Patient-Derived Xenograft Mice}

The employment of patient-derived xenograft (PDX) mice shows several advantages over cell-line-derived xenografts: (1) maintenance of genetic and epigenetic abnormalities and clonal 
heterogeneity existing in the primary tumors; (2) stroma cells from the tumor can be implanted, mimicking the tumor microenvironment; and (3) stronger predictive results that might aid in choosing the best therapeutic strategy for the patient.

An interesting study by Hou and collaborators described the results from a quantitative analysis of miRNA abundance in the liver and identified miR-199a/b-3p as the third most highly expressed miRNA resulting in deregulated in almost all HCC cases, independently from etiologic factors. Interestingly, nine miRNAs accounted for $88.2 \%$ of the liver miRNAome and specifically miR-122, miR-192, and miR-199a/b-3p represented 52\%, 16.9\%, and 4.9\%, respectively. In addition, epigenetic modifications of histones mediated miR-199a/b-3p downregulation in HCC, which was associated with decreased tumor-free results and overall survival in two patient cohorts, activating the oncogenic Raf/MEK/ERK signaling cascade. Regarding in vivo models, a patient-derived mouse model was established by subcutaneous transplantation of fresh tumor tissue in nude mice and masses propagated by sequential subcutaneous passages. Different miRNA delivery strategies were assayed, consisting of intratumoral injection of cholesterol-conjugated miR-199a/b-3p mimics or AAV vector particles inhibiting tumor growth, decreasing AFP levels, and causing tumor necrosis. In addition, AAV-mediated miR-199a/b-3p delivery by a single tail-vein injection in patient-derived orthotopic mice showed increased miRNA levels in tumor tissue, together with reduced tumor size, demonstrating the efficacy and nontoxicity of AAV8 vector system for potential HCC gene therapy [46]. Findings here obtained with miR-199a-3p-based therapeutics agree with those reported in the TG221 mice, proving the reliability of these animal models and suggesting miR-199a-3p replacement as a promising therapeutic option for human HCC [19].

In this scenario, the targeting of multiple oncogenic miRNAs by lncRNA-based vector engineering is emerging as a winning and innovative therapeutic strategy avoiding cancer cells to bypass the inhibition of a single miRNA and regain their proliferation capabilities. Li and coworkers generated an artificially designed interfering long noncoding RNA (lncRNAi), which contains the complementary sequences to multiple oncomiRs, competing with their target genes to bind to and consume oncomiRs inside HCC cells. Among oncomiRs overexpressed in HCC, this lncRNAi oncolytic vector was designed to selectively target miR-21, miR-221/222, miR-224, miR17-5p/20a, miR-10b, miR-106b, miR-151-5p, miR-155, miR-181a/181b, miR-184, miR-1, and miR-501-5p and showed multiple effects on transduction pathways, playing a key role in proliferation, invasion, and apoptosis of HCC cells. Two animal models were employed in this study (xenograft and PDX mice), one receiving intratumoral injection of lncRNAi oncolytic vectors and the other control vectors. A significant decrease of tumor growth was observed in both models, showing a decrease of target miRNAs and a correspondent increase of the most representative target genes, 27 and PTEN, highlighting this multi-miRNAs-based approach as a promising strategy with a greater anticancer efficacy in HCC [69].

\section{Orthotopic Mice}

Considering the importance of tumor microenvironment or tumor 'niche' for malignant transformation of normal hepatocytes and for development and progression of tumor nodules, the employment of orthotopic xenografts should be favored when testing drugs acting on tumor microenvironment. An innovative in vivo bioengineering approach has been established for the development of miRNA-based cancer therapies, producing a panel of biologic miRNA/siRNA molecules containing a common tRNA/pre-miR-34a molecular scaffold expressed at high levels by Escherichia coli fermentation. The production of these oligonucleotides in living cells guarantees minimal post-transcriptional modifications with respect to heavy chemical modifications applied to oligonucleotides produced by chemical synthesis; moreover, their correct processing and specific activity have been reported in human cells [70]. Interestingly, bioengineered let-7c displayed the highest antiproliferative activity against Huh-7 cells and reduced protein levels of validated targets, such as LIN28B, c-Myc, AT-rich interactive domain-containing protein 3B (ARID3B), and Bcl- $x l$, in both Hep3B and Huh-7 cells, as well as stem-cell properties of Huh-7 cells. An orthotopic HCC xenograft 
model was employed to test in vivo the efficacy of a lypopoliplex (LPP)-let-7c formulation, displaying a significant reduction of tumor burden associated with decreased AFP serum levels and increased apoptotic markers. LPP-formulated let-7c nanotherapeutics were well tolerated in vivo, showing minimal immunogenicity in human peripheral blood mononuclear cells and immunocompetent mice and holding great promise for the development of miRNA-based therapeutic options entering clinical experimentation [25].

A crucial aspect regarding gene replacement therapy is represented by the abundance of gene expression in normal tissue, reducing the risk of side effects, favoring treatment tolerance, and restricting antiproliferative and proapoptotic effects to cancer cells. miR-26 is expressed at high levels in several tissues but is downregulated in liver tumors, altering cell proliferation of HCC cells through direct targeting of cyclins D2 (CCND2) and E2 (CCNE2). The antitumorigenic effect of AAV-mediated miR-26 replacement strategy was previously reported in a $c-M Y C$ transgenic model of liver cancer, resulting in inhibition of cancer cell proliferation and tumor progression [26]. In addition, Jin et al. reported that miR-26 restoration is able to promote doxorubicin sensitization through autophagy inhibition by direct targeting of Unc-51 like autophagy activating kinase 1 (ULK1) gene that is responsible for autophagosome enucleation regulating initial steps of autophagic program. In particular, an orthotopic mouse model was established by implanting HepG2 cells in livers of nude mice, showing that miR-26 was able to increase drug sensitivity by blocking autophagy and therefore reducing tumor cell proliferation and triggering apoptotic cell death [27]. Notably, miR-26 family members were also downregulated in our DEN-HCC rat model (miR-26a-5p and miR-26b-5p; raw data are available in ArrayExpress repository, accession number E-MTAB-7624), again highlighting the similarities between rodent and human HCC biology and emphasizing the importance of a thoughtful animal model choice when translational studies are concerned, privileging studies with at least two different preclinical models.

\section{Rat Models}

HCC rat models do not allow genetic manipulation as mouse models do. However, execution of specific treatments such as transcatheter arterial chemoembolization (TACE), bile duct ligation, and surgical procedures are easier in rats than in mice [71]. Same applies to noninvasive monitoring of HCC development by ultrasound (US). HCC rat models display a high analogy to histopathological progression of human HCC and are of great value to identify effective anticancer treatments. Here, we describe the most characterized rat models in terms of molecular match with human HCC and miRNA deregulation: the DEN-HCC and the resistant-hepatocyte (R-H) rat models. We also report data about cirrhotic rats developing HCC, which were investigated to test miRNA-based therapeutic approaches.

\section{Chemically Induced Rat Model}

Due to the essential role of the liver in metabolism and detoxification, several chemical agents inducing liver injury are used as HCC promoters. DEN is a chemical carcinogen with the potential to cause tumors in various organs, including the liver, gastrointestinal tract, and respiratory tract [72]. DEN causes genomic mutations by inducing ethyl adducts and alkylation at many DNA positions [73]. Initiation of carcinogenesis, promotion, and progression can be produced by modulating DEN dosage [72]; in fact, it can induce benign and malignant liver lesions in rats with a high success and a low mortality rate, providing a model that simulates the lesions occurring in human liver. Induction of HCCs is usually obtained by administering DEN in the drinking water $(100 \mathrm{mg} / \mathrm{L})$ for eight weeks and one month after the last day of DEN administration multiple nodules can be observed with a size ranging from 2 to $10 \mathrm{~mm}$ in diameter [74,75]. By using this approach, we obtained rat HCCs sharing histopathological features of human HCC (Figure 2). Other protocols of DEN administration, such as injection ( $30 \mathrm{mg} / \mathrm{kg}$ body weight twice a week for 11 weeks), followed by a further nine weeks of observation, were also used, and they were reported to reproduce the inflammation-fibrosis-cancer stepwise histopathological progression similar to human HCC [76]. 

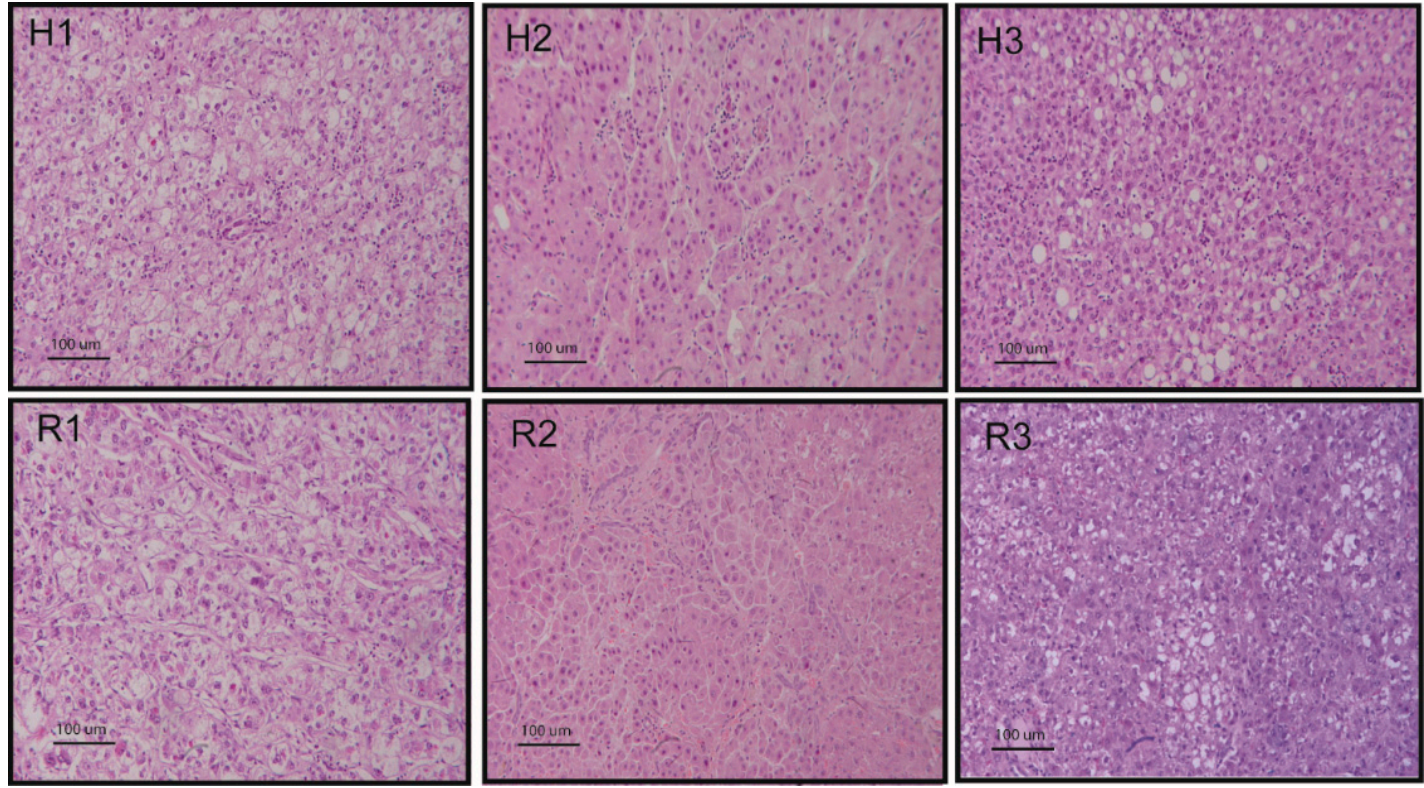

Figure 2. Features of human and rat hepatocellular carcinoma. Hematoxylin-eosin staining of human (H1-H3) and rat (R1-R3) HCC showing common histopathological features. (H1-R1) Clear cell variant caused by glycogen or lipid accumulation. (H2-R2) Trabecular growth pattern. Neoplastic hepatocytes, with nuclear irregularity, are arranged in trabeculae larger than three cell plates. (H3-R3) Progression toward less-differentiated histopathological grades is marked by the appearance of irregular nuclei, nuclear, and cellular pleomorphism, frequent mitosis, and loss of trabecular or pseudoglandular structures. Original magnification 40×. Scale bars: $100 \mu \mathrm{m}$.

DEN models have been used in many studies aiming at HCC characterization. Next-generation sequencing (NGS) technologies provided new opportunities to identify HCC molecular signatures contributing to treatment optimization. In this context, we compared transcriptomic data from human and DEN-induced rat HCCs. Among common deregulated genes, the activation of Notch pathway and the aberrant expression of a panel of HCC-associated miRNAs (e.g., miR-122, miR-221, and let-7a) suggested this model to be suitable to explore miRNA contribution to disease progression and treatment response [77-79]. Remarkably, most of miRNAs deregulated in the DEN-induced rat model are aberrantly expressed in human HCC cohorts from several studies, as summarized in Tables 1 and 2. In particular, members of both paralogous clusters, miR-17-92 and miR-25-106b, showing oncogenic properties [54], were upregulated in our DEN-HCC rat model (miR-18a-5p and miR-106b-5p; raw data are available in ArrayExpress repository, accession number E-MTAB-7624), as well as in our HCC patient datasets (miR-18a and miR-25) [3]. Similarly, miR-122 was downregulated in 70\% of rat DEN-HCCs (unpublished data from our group) and in the same percentage of human HCCs [3]. Let-7 miRNA family, miR-26a, and miR-145 were also downregulated in the rat model mirroring human HCC (Tables 1 and 2).

Table 1. miRNA downregulated in the Diethylnitrosamine-Hepatocellular carcinoma (DEN-HCC) rat model.

\begin{tabular}{|c|c|c|c|c|c|}
\hline $\begin{array}{l}\text { Rat Deregulated } \\
\text { miRNA }\end{array}$ & $\begin{array}{c}\text { Fold Change } \\
\text { (HCC/Surrounding Liver) }\end{array}$ & $p$-Value & $\begin{array}{c}\text { Deregulation in } \\
\text { Human HCC }\end{array}$ & $\begin{array}{l}\text { Target Genes in } \\
\text { Human HCC }\end{array}$ & References \\
\hline rno-miR-378a-5p & 18.3 & $<0.0001$ & NA & NA & NA \\
\hline rno-miR-22-5p & 11.9 & 0.012 & NA & NA & NA \\
\hline rno-miR-338-3p & 11.5 & 0.0017 & $\begin{array}{c}\text { DOWN; DOWN; } \\
\text { NA }\end{array}$ & $\begin{array}{l}\text { NA; HIF1A; } \\
\quad P K L R\end{array}$ & [80-82] \\
\hline rno-miR-455-3p & 10.1 & 0.0011 & DOWN & STK17B & [83] \\
\hline rno-miR-144-3p & 8.7 & 0.0011 & DOWN; DOWN & SMAD4; CCNB1 & {$[84,85]$} \\
\hline
\end{tabular}


Table 1. Cont.

\begin{tabular}{|c|c|c|c|c|c|}
\hline $\begin{array}{l}\text { Rat Deregulated } \\
\text { miRNA }\end{array}$ & $\begin{array}{c}\text { Fold Change } \\
\text { (HCC/Surrounding Liver) }\end{array}$ & $p$-Value & $\begin{array}{l}\text { Deregulation in } \\
\text { Human HCC }\end{array}$ & $\begin{array}{l}\text { Target Genes in } \\
\text { Human HCC }\end{array}$ & References \\
\hline rno-miR-203a-3p & 7.7 & 0.014 & DOWN & GPC3 & [86] \\
\hline rno-miR-352 & 6.3 & 0.0098 & & Rodent-specific miRNA & \\
\hline rno-miR-30b-3p & 6.2 & 0.0040 & NA & NA & NA \\
\hline rno-miR-10b-5p & 5.6 & 0.012 & UP; UP & HOXD10; CSMD1 & {$[87,88]$} \\
\hline rno-miR-99a-3p & 5.6 & 0.0016 & NA & NA & NA \\
\hline rno-miR-210-3p & 5.5 & 0.0083 & UP; UP & VMP1; HIF3A & {$[89,90]$} \\
\hline rno-miR-362-3p & 5.1 & 0.0083 & UP; DOWN & TOB2; RAB23 & {$[91,92]$} \\
\hline rno-miR-30e-3p & 5.0 & 0.0061 & NA & NA & NA \\
\hline rno-miR-511-3p & 4.7 & 0.0083 & DOWN; DOWN & $\mathrm{NA} ; A K T 1$ & {$[93,94]$} \\
\hline rno-miR-193-5p & 4.3 & $<0.0001$ & DOWN; DOWN & NA; SPOCK1 & {$[95,96]$} \\
\hline rno-miR-33-5p & 4.1 & 0.0021 & NA & NA & NA \\
\hline rno-miR-192-3p & 4.1 & 0.0056 & NA & NA & NA \\
\hline rno-miR-3547 & 3.7 & 0.0059 & \multicolumn{3}{|c|}{ Not annotated human miRNA } \\
\hline rno-miR-145-5p & 3.7 & 0.011 & $\begin{array}{l}\text { DOWN; DOWN; } \\
\text { DOWN; DOWN }\end{array}$ & NA; IRS1; IRS2; NA & {$[3,58,97,98]$} \\
\hline rno-miR-378b & 3.5 & 0.0039 & NA & NA & NA \\
\hline rno-miR-122-3p & 3.1 & 0.0068 & DOWN & MDM2 & [99] \\
\hline rno-miR-339-3p & 3.0 & 0.016 & NA & NA & NA \\
\hline rno-miR-30a-3p & 3.0 & 0.012 & DOWN & NA & [100] \\
\hline rno-miR-101a-3p & 2.6 & 0.0010 & $\begin{array}{l}\text { DOWN; DOWN; } \\
\text { DOWN }\end{array}$ & $\mathrm{MCl}-1 ; \mathrm{SOX} 9 ; \mathrm{EZH} 2$ & [101-103] \\
\hline rno-miR-193-3p & 2.4 & 0.0011 & $\begin{array}{c}\text { DOWN; } \\
\text { DOWN; NA }\end{array}$ & $u P A ; \mathrm{NA} ; \mathrm{CCND} 1$ & {$[95,104,105]$} \\
\hline rno-miR-365-3p & 2.2 & 0.013 & $\begin{array}{l}\text { DOWN; DOWN; } \\
\text { DOWN }\end{array}$ & $\mathrm{NA} ; A D A M 10 ; R A C 1$ & [106-108] \\
\hline rno-miR-347 & 2.2 & 0.0047 & \multicolumn{3}{|c|}{ Not annotated human miRNA } \\
\hline rno-miR-7a-1-3p & 2.1 & 0.017 & \multicolumn{3}{|c|}{ Not annotated human miRNA } \\
\hline rno-miR-125b-5p & 2.1 & 0.0044 & $\begin{array}{c}\text { DOWN; DOWN; } \\
\text { DOWN; DOWN; } \\
\text { DOWN }\end{array}$ & $\begin{array}{l}\text { NA; } L I N 28 B ; \\
P l G F ; B c l-2 ; \\
\text { NA }\end{array}$ & [109-113] \\
\hline rno-miR-122-5p & 2.1 & $<0.0001$ & DOWN; DOWN & $\begin{array}{c}\text { CGN1; ADAM10, SRF, } \\
\text { Igf1R }\end{array}$ & {$[3,114]$} \\
\hline rno-miR-140-3p & 2.0 & 0.016 & NA & GRN & [115] \\
\hline rno-miR-101b-3p & 1.9 & 0.0054 & $\begin{array}{c}\text { DOWN; DOWN; } \\
\text { DOWN }\end{array}$ & $\begin{array}{c}\mathrm{MCl}-1 ; \mathrm{SOX} 9 \\
\mathrm{EZH} 2\end{array}$ & [101-103] \\
\hline rno-miR-10a-5p & 1.8 & 0.015 & $\mathrm{UP} ; \mathrm{NA}$ & EphA4; NCOR2 & {$[116,117]$} \\
\hline rno-miR-22-3p & 1.8 & 0.0041 & $\begin{array}{l}\text { DOWN; DOWN; } \\
\text { DOWN }\end{array}$ & HDAC4; YWHAZ; CD147 & [118-120] \\
\hline rno-miR-26b-5p & 1.8 & $<0.0001$ & $\begin{array}{l}\text { DOWN; DOWN; } \\
\text { DOWN; DOWN }\end{array}$ & $\begin{array}{l}\text { CDK6, CCNE1; USP9X; } \\
\text { SMAD1; ULK1 }\end{array}$ & {$[27,121-123]$} \\
\hline rno-miR-26a-5p & 1.7 & 0.013 & $\begin{array}{l}\text { DOWN; DOWN; } \\
\text { DOWN; DOWN; } \\
\text { DOWN; DOWN }\end{array}$ & $\begin{array}{c}\text { CCND2, CCNE2; CDK6, } \\
\text { CCNE1; } \\
\text { IL6; VEGFA; ITGA5; } \\
\text { ULK1 }\end{array}$ & {$[26,27,121,124-126]$} \\
\hline rno-miR-99a-5p & 1.7 & 0.0013 & $\begin{array}{l}\text { DOWN; DOWN; } \\
\text { DOWN }\end{array}$ & $\begin{array}{c}\text { MTOR, IGF-1R; PLK1; } \\
\text { AGO2 }\end{array}$ & [127-129] \\
\hline rno-miR-451-5p & 1.6 & 0.011 & $\begin{array}{l}\text { DOWN; DOWN; } \\
\text { DOWN; DOWN }\end{array}$ & $\begin{array}{c}\text { IKBKB; } A T F 2 ; c-M y c ; \\
\text { YWHAZ }\end{array}$ & [130-133] \\
\hline rno-miR-30e-5p & 1.6 & 0.003 & DOWN & MTA1 & [134] \\
\hline rno-miR-192-5p & 1.6 & $<0.0001$ & $\begin{array}{l}\text { DOWN; DOWN; } \\
\text { DOWN }\end{array}$ & ZEB1; SLC39A6; HOTTIP & [135-137] \\
\hline rno-miR-140-5p & 1.6 & 0.0028 & $\begin{array}{l}\text { DOWN; DOWN; } \\
\text { DOWN }\end{array}$ & $\begin{array}{l}\text { TGFBR1, FGF9; Pin1; } \\
\text { FEN1 }\end{array}$ & [138-140] \\
\hline rno-miR-345-5p & 1.5 & 0.0046 & DOWN; DOWN & IRF1; YAP1 & {$[141,142]$} \\
\hline rno-miR-30d-5p & 1.5 & 0.0097 & $\mathrm{UP} ; \mathrm{UP}$ & GNAI2; GLDC & {$[8,143]$} \\
\hline
\end{tabular}

NA: data not available; UP: upregulated miRNAs in human cohorts; DOWN: downregulated miRNAs in human cohorts. 
Table 2. miRNA upregulated in the DEN-HCC rat model.

\begin{tabular}{|c|c|c|c|c|c|}
\hline $\begin{array}{l}\text { Rat Deregulated } \\
\text { miRNA }\end{array}$ & $\begin{array}{c}\text { Fold Change } \\
\text { (HCC/Surrounding Liver) }\end{array}$ & $p$-Value & $\begin{array}{l}\text { Deregulation in } \\
\text { Human HCC }\end{array}$ & $\begin{array}{l}\text { Target Genes in } \\
\text { Human HCC }\end{array}$ & References \\
\hline rno-miR-146b-5p & 55.6 & $<0.0001$ & DOWN; DOWN & TRAF6; NA & {$[3,144]$} \\
\hline rno-miR-183-5p & 45.4 & $<0.0001$ & UP; UP & PDCD4; FOXO1 & {$[145,146]$} \\
\hline rno-miR-18a-5p & 14.2 & $<0.0001$ & UP; UP; UP & ESR1; KLF4; SOCS5 & [147-149] \\
\hline rno-miR-211-3p & 12.9 & 0.0073 & NA & NA & NA \\
\hline rno-miR-125a-3p & 10.8 & 0.0059 & NA & NA & NA \\
\hline rno-miR-182 & 8.3 & $<0.0001$ & UP; UP & MTSS1; FOXO1 & {$[146,150]$} \\
\hline rno-miR-1249 & 5.3 & 0.018 & NA & HNRNPK & [151] \\
\hline rno-miR-3473 & 4.1 & 0.0050 & \multicolumn{3}{|c|}{ Rodent-specific family } \\
\hline rno-miR-466b-5p & 3.2 & 0.016 & \multicolumn{3}{|c|}{ Rodent-specific family } \\
\hline rno-miR-466c-3p & 3.2 & 0.043 & \multicolumn{3}{|c|}{ Rodent-specific family } \\
\hline rno-miR-1949 & 3.0 & $<0.0001$ & \multicolumn{3}{|c|}{ Rodent-specific family } \\
\hline rno-miR-96-5p & 2.7 & $<0.0001$ & UP; UP & NA; FOXO1 & {$[12,146]$} \\
\hline rno-miR-15b-5p & 2.0 & $<0.0001$ & UP; UP; UP & $\begin{array}{l}\text { NA; Rab1A; } \\
\quad \text { NA }\end{array}$ & [152-154] \\
\hline rno-miR-93-5p & 1.9 & $<0.0001$ & UP; UP; UP & NA; PDCD4; NA & {$[12,155,156]$} \\
\hline rno-miR-130a-3p & 1.8 & $<0.0001$ & DOWN; DOWN & NA; NA & {$[3,157]$} \\
\hline rno-miR-106b-5p & 1.8 & $<0.0001$ & UP; UP; UP & $\begin{array}{l}\text { NA; DR4; } \\
\text { PTEN }\end{array}$ & [158-160] \\
\hline rno-miR-25-3p & 1.7 & $<0.0001$ & UP; UP & RhoGDI-1; SOCS5 & {$[149,161]$} \\
\hline rno-miR-31a-5p & 1.7 & 0.0076 & UP; DOWN & $\mathrm{NA} ; H D A C 2, C D K 2$ & {$[162,163]$} \\
\hline rno-miR-29b-3p & 1.5 & 0.023 & DOWN; DOWN & Bcl-2, Mcl-1; LOXL2 & {$[164,165]$} \\
\hline
\end{tabular}

NA: data not available; UP: upregulated miRNAs in human cohorts; DOWN: downregulated miRNAs in human cohorts.

The DEN-induced HCC rat model was also used to examine pathways involved in sorafenib response, showing the modulation of apoptotic and proliferative pathways, and to test the therapeutic role of siRNAs/miRNAs. In particular, miRNAs are more attractive than siRNAs due to their simultaneous effects on different pathways. Interestingly, compound Astragalus and Salvia miltiorrhiza extract (CASE) containing active principles extracted from Astragalus membranaceus and Salvia miltiorrhiza provided anticancer therapy more likely through miR-145 and miR-21 upregulation and downregulation, respectively [166].

miR-494 is overexpressed in the great majority of rat DEN-induced HCCs, and its expression correlates with stem-cell features, representing an appropriate model for studying molecular alterations occurring in the stem-cell-like HCC subgroup with miR-494 aberrant expression and poor survival $(25 \%$ of human HCCs) [15]. Pollutri et al. also demonstrated an antitumor effect of a sorafenib-combined anti-miR-494 strategy in DEN HCC rats, showing decreased tumor progression with respect to sorafenib monotherapy. miR-494-mediated mTOR pathway activation was responsible for decreased sorafenib sensitization in HCC preclinical models; indeed, rapamycin co-administration triggered apoptotic cell death in miR-494 overexpressing HCC cells, as evidenced by Poly adenosine diphosphate [ADP-ribose] polymerase 1 (PARP-1) and caspase-3 specific cleavage. Remarkably, all these findings were replicated in xenograft mice, emphasizing the usefulness of both models for HCC preclinical studies. In the same model, miR-221 overexpression associated with sorafenib resistance and caspase-3 was recognized as its target gene, contributing to miR-221 anti-apoptotic activity and drug-resistant phenotype. Notably, an association between high miR-221 or low caspase-3 levels and tumor multifocality was assessed in human HCC specimens, suggesting the robustness and specificity of preclinical data and their reliability with respect to the human pathology [167].

Chemically induced models are advantageous to study HCCs developed in a natural background of liver damage. However, age of the animals and hepatotoxins concentration might lead to different tumor phenotypes, influencing experimental outcomes. Remarkably, DEN-induced liver tumors 
were responsive to sorafenib treatment, whereas orthotopically implanted rat HCCs were not [168]. These findings point out differences in treatment responses between models that might be related to tumor microenvironment and might have a translational impact. As observed for mouse models, the relevance of cirrhosis in the natural history of human HCC development has prompted researchers to recreate this background in laboratory models, too. Experimental approaches used to induce liver damage progressing to cirrhosis in rats include heterogeneous protocols of exposure to CCl4, DEN, bile duct ligation, or a combination of these [169]. Some studies performed in HCC rat models arising on cirrhosis have specifically addressed the role of miRNAs as possible treatments for helping liver regeneration of non-neoplastic hepatocytes after partial hepatectomy, without triggering proliferation of residual HCC cells. Indeed, the impaired regenerative ability of cirrhotic liver following liver resection still represents an important risk factor for post-hepatectomy liver failure. In the study by Chen and coworkers, liver cirrhosis was induced by intraperitoneal injection of 50\% CCl4-olive-oil solution in adult male Wistar rats [170]. In a first study conducted in cirrhotic rats undergoing partial hepatectomy, miR-203 mimics enhanced proliferative signals promoting liver regeneration such as IL6/STAT3, favoring the proliferation of normal hepatocytes. Even more interestingly, the same research group further demonstrated a dual role of miR-203 by addressing the problem of HCC control after partial hepatectomy, which may trigger growth and metastasis of residual HCC cells. In particular, Zheng et al. induced cirrhosis and HCC through a sequential exposure of CCl4 and DEN, reproducing progression of HCC in human cirrhotic livers [171]. These Authors confirmed miR-203 as an enhancer of liver regeneration after $70 \%$ hepatectomy through targeting of IL-6/SOCS3/STAT3 signaling. At the same time, they demonstrated a tumor suppressive effect of miR-203 on HCC cells. Indeed, miR-203 mimics inhibited proliferation, invasion, and lung metastasis of residual HCC cells by suppressing epithelial-to-mesenchymal transition (EMT) through IL-1b, Snail1, and Twist1 targeting. The dual role of miR-203 is not so unexpected; indeed, the same miRNA may act in opposite ways not only in different tissues, but also in the same tissue, depending on the constitutive expression of targets.

\section{R-H Rat Model}

Hepatocarcinogenesis is a multistep process characterized by the progressive accumulation of genetic mutations, epigenetic changes, and chromosomal rearrangements that, together with chromatin instability, give rise to hepatocyte transformation and the onset of heterogeneous tumors. Because of limitations associated with tissue availability at early stages, animal models that fully recapitulate HCC history represent valuable tools for comprehensive studies on molecular alterations involved in its early development. The resistant-hepatocyte $(\mathrm{R}-\mathrm{H})$ rat model consists of a single carcinogenic dose of DEN followed by a short-term dietary exposure to 2-acetylaminofluorene (2-AAF) that suppresses growth of virtually all normal hepatocytes, combined to partial hepatectomy (2/3 of rat liver) to sharpen the rapid proliferation of DEN-altered hepatocytes. After one week from partial hepatectomy, hepatic foci will continue to proliferate, becoming the precursor lesions that, only in part, will evolve into HCC nodules [172]. This rat model represents an ideal preclinical tool for the study of molecular events occurring at very early stages of hepatocarcinogenesis, allowing the identification of phenotypically distinct lesions that can be easily isolated by means of laser capture microdissection (LCM). The evolution of preneoplastic lesions has been characterized as showing a positivity for the hepatocyte progenitor cell marker, cytokeratin-19 (CK19), in 25\% of preneoplastic nodules, in 50\% of persistent lesions, and in all HCCs, demonstrating that CK19-positive preneoplastic lesions are more likely the progenitor of HCC in this model. Comparative functional genomics showed that CK19-associated gene signature could predict clinical outcomes of HCC patients, representing an ideal model for the study of the HPC-derived HCC subclass [173]. miRNA and gene-expression profiling identified the activation of nuclear factor erythroid related factor 2 (NRF2) pathway and upregulation of miR-200a as the prevalent molecular alterations occurring at very early stages of tumorigenesis and maintained throughout the carcinogenic process. NRF2 is an integrated redox signaling system controlled by Kelch-like $\mathrm{ECH}$-associated protein 1 (KEAP1), which promotes its proteasome-mediated degradation and whose 
regulation is modulated by miR-200a itself. The association between miR-200a/KEAP1/NRF2 axis and tumorigenic potential was proven by in vivo experiments, showing that NFR2 pathway is turned off during tumor regression of HCC nodules. Because of the high concordance between altered genes in rat and human tumors, the $\mathrm{R}-\mathrm{H}$ model also represents an ideal tool for the detection of miRNA alterations occurring at very early stages of cancer development and for the identification of target genes and innovative therapeutic strategies [174]. In addition, the activation of NRF2 pathway is also responsible for the upregulation of glucose-6-phosphate dehydrogenase (G6PD), a key enzyme implicated in metabolic shift or 'Warburg effect', through miR-1 inhibition [175]. High G6PD expression levels were detected in CK19-positive lesions and early preneoplastic foci, but not in CK-19-negative lesions, and, in line, increased G6PD mRNA levels were observed in two HCC patient cohorts where it positively correlated with CK19 expression, higher tumor grade, and increased metastasis formation. In agreement, a negative correlation between miR-1 and G6PD was identified in CK19-positive lesions, and lower miR-1 levels were quantified in human HCCs with respect to surrounding livers, confirming the high concordance in terms of dysregulated pathways between aggressive preneoplastic rat lesions and human HCCs [176]. Interestingly, a global proteomic analysis from glutathione S-transferase-P (GST-P) positive laser micro-dissected nodules identified G6PD among protein markers discriminating $\mathrm{R}-\mathrm{H}$ model-derived focal lesion from normal liver with or without progenitor cell activation, demonstrating LCM coupled with mass-spectrometry-based proteomics as an effective approach to characterize preneoplastic lesions and to identify early diagnostic markers for effective clinical intervention. In addition, mTOR pathway was found activated at early stages of carcinogenesis and, consistently, its transient inhibition by rapamycin treatment impaired the growth of focal lesions and induced a less aggressive phenotype attenuating the loss of differentiating functions, as detected by both transcriptomic and proteomic genome-wide analyses $[177,178]$. The AKT/mTOR pathway is frequently activated in HCC, characterizing a subgroup of patients with a high proliferation signature and sorafenib resistance [179-181]. Several miRNAs contribute to its post-transcriptional regulation mediating sorafenib resistance in preclinical models, highlighting its central role in HCC progression and treatment escape $[11,15,68,114,167]$. Interestingly, the R-H model is also suitable for the investigation of oval cell population, due to its rapid expansion following partial hepatectomy. The Hippo pathway is required for the repression of oval cells that represent the adult liver's stem-cell compartment. An accumulation of YAP1, a transcriptional co-activator of the Hippo pathway, was detected in preneoplastic foci, representing a very early event in hepatocarcinogenesis. On the contrary, a decrease of miR-375 was found in rat early lesions, suggesting its contribution to YAP1 accumulation and HCC development and confirming its role as a TS miRNA in HCC [182]. Remarkably, the downregulation of thyroid hormone receptor beta (THRB) was identified as an early event in the $\mathrm{R}-\mathrm{H}$ model, but it was not associated with genetic mutations or DNA methylation of its promoter region. On the other end, among miRNAs directly targeting THRB mRNA, miR-27a, miR-181a, miR-146a, and miR-204 were upregulated in rat HCCs, and, in particular, miR-27a showed an inverse correlation with THRB levels and inhibited its expression in HCC cell lines. Regarding human HCC, reduced expression of THRB target genes, iodothyronine deiodinase 1 (DIO1) and G6PC, was confirmed in cirrhotic samples with respect to normal livers, suggesting the alteration of this pathway as an early event in human HCCs, as well. In agreement, an upregulation of miR-181a, miR-27, and miR-204 was detected in surrounding cirrhotic livers, more likely contributing to THRB modulation in liver cirrhosis and increasing HCC risk development due to the so-called 'field effect', further strengthening the similarities between the RH-model and the human counterpart [183]. Similarly, Brockhausen and coworker reported the increased expression of miR-181a in human and rodent cirrhotic livers when compared to normal livers and demonstrated its involvement in TGF- $\beta$-mediated EMT in immortalized non-neoplastic human hepatocytes [184]. TGF- $\beta$ is a signaling pathway strongly activated in chronic liver disease, further supporting the possible role for miR-181a in neoplastic transformation in a milieu of chronic inflammation [184,185]. In addition, lncRNA CCAT1 was demonstrated among molecular mechanisms contributing to miR-181a deregulation through a sponging activity leading to increased 
cell proliferation and ATG7-mediated autophagy of HCC cells [186]. Concerning autophagy, the $\mathrm{R}-\mathrm{H}$ rat model was employed to investigate whether its dysregulation might occur at early stages of liver carcinogenesis. Controversial data report the dual role of autophagy in cancer, acting both as a cell survival process and as a tumor suppressor pathway, likely suppressing tumor growth at early stages and favoring cell proliferation and energy supply at later stages [187]. The study by Kowalik and coauthors reported an impairment of autophagy in preneoplastic lesions characterized by accumulation of abnormal mitochondria and autophagic vacuoles with partially degraded material, displaying an early deregulation of autophagy during hepatocarcinogenesis. An increase of autophagic markers, Ambra1, Beclin1, and p62 was detected in CK19-positive nodules only. Strikingly, a 150-fold upregulation of the oncogenic autophagy-related miRNA, miR-224, was detected in these lesions, and its accumulation is more likely associated with the deregulation of autophagic machinery. In vivo experiments with amiodarone, an autophagic inducer, showed augmented tumor progression with increased size of CK19-positive lesions, and, vice versa, treatment with the autophagy inhibitor chloroquine reduced size and percentage of CK19-positive nodules [188]. Due to the contradictory role of autophagy in tumorigenesis, particular attention should be given when a pharmacological strategy is concerned, considering the employment of different animal models to better guarantee the translation of preclinical findings into the clinics. Others and our group compared this model with the rat DEN HCCs and described similar alterations, which were confirmed in patient cohorts, as well, emphasizing the robustness of these preclinical tools. Specifically, a prominent downregulation of the 2-hydroxy acid oxygenase (HAO2) was observed in the R-H rat model at both early and advanced stages of carcinogenesis. HAO2 was significantly downregulated in $100 \%$ of animals from two other HCC rat models, as well as in two mouse models of HCC (with and without DEN administration), and in human HCCs, demonstrating HAO2 repression as a general mechanism contributing to liver cancer development more likely due to reduced reactive oxygen species levels in transformed cells [189]. A time-course gene-expression profile for Aldo-keto reductase $(A k r)$ family members in preneoplastic and tumor lesions identified the upregulation of six of its members in the $\mathrm{R}-\mathrm{H}$ rat model, representing possible markers of early diagnosis. This enzyme superfamily contributes to the metabolism of steroids, carbohydrates, prostaglandins, aldehydes, and ketones, and their high representation in HCC has been previously reported by proteomic investigations [190]. The overexpression of two out of six members was confirmed in DEN-HCC rats and in human liver biopsies at both mRNA and protein levels, and, as mentioned above, NRF2 nuclear translocation was detected in tumor samples, confirming the central role of this transcription factor in promoting liver cancer [191]. In conclusion, the R-H rat model represents a helpful tool for the discovery of dysregulated events occurring at early stages of tumorigenesis, showing a high translational potential because of great representativeness of molecular pathways altered in human HCC.

\section{Zebrafish}

Although zebrafish are less complex than humans, their liver is similar in structure to a mammalian liver, with biliary epithelial cells, sinusoidal endothelial cells, and hepatic stellate cells that support hepatocytes [192]. A zebrafish liver develops HCC similar to human liver, and it can be used to study putative driver mutations found in HCC. Zebrafish and human HCCs share overlapping expression profiles of genes involved in apoptosis, DNA replication, cell adhesion, metastasis, cytoskeletal organization, cell motility, cell cycle/proliferation, RNA processing, and protein synthesis. Thus, zebrafish liver tumors are highly analogous to human HCC in terms of comparative analyses of microarray data [193]. Upregulated and downregulated genes in zebrafish liver tumors are also constantly upregulated and downregulated in human HCCs [194]. MicroRNAs are known to be evolutionary conserved across species. Among them, miR-122 was found to be conserved in 12 different species, including humans, frogs, and zebrafish, and it is involved both in human and zebrafish hepatocytes differentiation $[195,196]$. Moreover, several putative target genes of the miR-1, miR-146, and $\mathrm{miR}-221 / \mathrm{miR}-222$ families are conserved between human and zebrafish. Hepatocyte differentiation 
is directed by a positive-feedback loop that includes the transcription factor (HNF6) and microRNA (miR-122), both in human and in zebrafish liver [197]. According to its tumor-suppressor function in human HCC, miR-145 expression regulates zebrafish embryonic liver size by controlling hepatocyte proliferation [198]. Functional analysis in zebrafish shows that miR-30a is required for normal hepatobiliary development, suggesting a similar critical role in mammalian hepatogenesis [199]. The conserved expression signatures of these miRNAs and the involvement of their predicted target genes in cancer support zebrafish as a model of liver cancer representative of the human counterpart.

Following injection of the human HCC cell line JHH6 into the yolk sack of Zebrafish larvae, Tonon et al. confirmed this model as a useful setting to test therapeutic molecules for HCC [200]. Moreover, injecting human cancer cells into zebrafish embryos when the immune response is not yet established, prevents their rejection. More recently, small molecules with strong anticancer therapeutic potential and better therapeutic index than sorafenib were identified by using a zebrafish drug-screening platform [201]. As reported in others HCC animal models, the role of metformin on HCC tumor surveillance was also demonstrated [202]. Interestingly, as observed in humans, male fish developed HCC faster than females due to sex hormone imbalance via noncanonical estrogen signaling, including $\mathrm{G}$ protein-coupled estrogen receptor 1 (GPER) [203]. In line, fish treated with $17 \beta$-estradiol developed more tumors than controls, and this effect was evident in particular in male cohorts [204]. Together with transgenic technology, several inducible expression systems are available for zebrafish. Among them, a transgenic model expressing kRAS develops liver tumors and appears to be representative of those human HCCs activating Ras signaling, which account for up to $50 \%$ of cases [205,206]. Transgenic expression of HBx in a TP53 mutant background induces HCC in $44 \%$ of fish, whereas zebrafish expressing HCV core protein swiftly develop HCC when exposed to carcinogens $[207,208]$. Up to $40 \%$ of human HCCs result from activating mutations in the gene encoding for $\beta$-catenin (CTNNB1). The zebrafish model was used to prove that activated $\beta$-catenin expression in a small subset of hepatocytes is sufficient to drive HCC initiation [209]. Zebrafish are effective as disease models because of their high fecundity, low housing cost, and transparency, which allows live imaging and is useful to explore mechanisms by which HBV and HCV induce HCC. Moreover, large experimental sample sizes are allowed, allowing informative studies. Finally, small molecules can be added directly to the zebrafish's water, thus avoiding the gavage often required in rodents. The disadvantages are mainly related to the low amounts of liver tissue available for different assays and the lack of antibodies able to recognize zebrafish antigens.

\section{Conclusions}

Advances in tumor biology have led to the identification of new targets that hold promise for ameliorating HCC patients' outcome. Translation of novel treatments requires preclinical testing in animal models mirroring human HCC. New approaches should be tested in specific models, identified on the basis of molecular matching. A wide range of rodent models of HCC is now available. Most of them were characterized from a molecular point of view, including miRNA aberrant expression. Remarkably, the multitargeting function of miRNAs make it mandatory to define the molecular context for each experimental purpose and to fully characterize each model not only for miRNA but also for targets expression, at least as far as the oncogenic drivers are concerned. Indeed, targeted treatments should be tested in models that are representative of specific HCC subgroups, in order to assess those settings in which they are awaited to work at their best.

The restoration of miR-199a-3p and miR-26a levels as promising miRNA-based anticancer strategies have been assayed in several HCC animal models by using different therapeutic approaches, such as miRNA mimics or AAV particles. On the other side, the silencing of onco-miR-221 holds great promise as a therapeutic option in the oncologic field. Indeed, miR-221 plays oncologic functions in almost all solid malignancies, and its inhibition represents a possible common strategy for different cancer types. Interestingly, the development of innovative strategies for the production of miRNA-modified molecules with a nonimmunogenic backbone to increase the stability in body fluids, and the engineering 
of nanoparticles for enhanced miRNA delivery, are further steps toward the translation of preclinical findings into the clinics.

Besides rodents, other models appear very interesting, such as, for example, zebrafish, which are easier to house, but they are still rarely adopted for preclinical studies on HCC.

In conclusion, HCC models focused to miRNA studies should be chosen based on a profound knowledge of the molecular context, with specific reference to expression assessment of oncogenic drivers targeted by the miRNA of interest. In addition, in HCC several deregulated miRNAs share common targets. Several oncogenic drivers are targeted by multiple deregulated miRNAs. This opens the door to combined approaches aimed at modulation of panels of critical miRNAs, instead of single miRNA. These combined approaches might help to control the well-known feedback loops elicited by miRNAs' enforced expression or inhibition, which may impair the success of miRNAs manipulation. Indeed, the complex action miRNAs, the modulation of many targets, sometimes with opposite functions, should always be kept in mind, in order to avoid unexpected results in the translational steps.

Funding: This research was funded by 1. Programma di Ricerca Regione-Università 2010-2012, Regione Emilia-Romagna, Bando "Alessandro Liberati", to F.F. "Identification of innovative microRNAs-based biomarkers and anti-cancer strategies for the treatment of Hepatocellular carcinoma". 2. Programma di Ricerca Regione-Università 2010-2012, Regione Emilia-Romagna, Bando "Ricerca Innovativa", to L.G. "Innovative approaches to the diagnosis and pharmacogenetic-based therapies of primary hepatic tumors, peripheral B and T-cell lymphomas and lymphoblastic leukaemias".

Conflicts of Interest: The authors declare no conflicts of interest.

\section{Abbreviations}

$\begin{array}{ll}\text { HCC } & \text { hepatocellular carcinoma } \\ \text { miRNA } & \text { microRNA } \\ \text { GEM } & \text { genetically engineered mouse } \\ \text { TG } & \text { transgenic } \\ \text { KO } & \text { knockout: } \\ \text { R-H model } & \text { resistant hepatocyte model } \\ \text { TS } & \text { tumor suppressor } \\ \text { HBV } & \text { hepatitis B virus } \\ \text { HCV } & \text { hepatitis C virus } \\ \text { NASH } & \text { nonalcoholic steatohepatitis } \\ \text { NAFLD } & \text { nonalcoholic fatty liver disease } \\ \text { CC14 } & \text { carbon tetrachloride } \\ \text { DEN } & \text { diethylnitrosamine } \\ \text { EMT } & \text { epithelial-to-mesenchymal transition } \\ \text { HFD } & \text { high-fat diet } \\ \text { c-Myc } & \text { avian myelocytomatosis virus oncogene cellular homolog } \\ \text { mTOR } & \text { mammalian target of rapamycin } \\ \text { Ras } & \text { Kirsten rat sarcoma viral oncogene homolog } \\ \text { PI3K } & \text { phosphoinositide 3-kinase } \\ \text { AFP } & \text { alpha-fetoprotein } \\ \text { Igf2 } & \text { insulin-like growth factor 2 } \\ \text { GPC3 } & \text { beta catenin: Ctnnb1; glypican 3 } \\ \text { PTEN } & \text { phosphatase and tensin homolog } \\ \text { CK19 } & \text { cytokeratin 19 } \\ \text { NRF2 } & \text { nuclear factor erythroid related factor 2 } \\ \text { G6PD } & \text { glucose-6-phosphate dehydrogenase } \\ \text { THRB } & \text { thyroid hormone receptor beta } \\ \text { TGF-b } & \text { transforming growth factor beta } \\ & \end{array}$




\section{References}

1. Liu, C.G.; Calin, G.A.; Meloon, B.; Gamliel, N.; Sevignani, C.; Ferracin, M.; Dumitru, C.D.; Shimizu, M.; Zupo, S.; Dono, M.; et al. An oligonucleotide microchip for genome-wide microRNA profiling in human and mouse tissues. Proc. Natl. Acad. Sci. USA 2004, 101, 9740-9744. [CrossRef] [PubMed]

2. Volinia, S.; Calin, G.A.; Liu, C.G.; Ambs, S.; Cimmino, A.; Petrocca, F.; Visone, R.; Iorio, M.; Roldo, C.; Ferracin, M.; et al. A microRNA expression signature of human solid tumors defines cancer gene targets. Proc. Natl. Acad. Sci. USA 2006, 103, 2257-2261. [CrossRef] [PubMed]

3. Gramantieri, L.; Ferracin, M.; Fornari, F.; Veronese, A.; Sabbioni, S.; Liu, C.G.; Calin, G.A.; Giovannini, C.; Ferrazzi, E.; Grazi, G.L.; et al. Cyclin G1 is a target of miR-122a, a microRNA frequently down-regulated in human hepatocellular carcinoma. Cancer Res. 2007, 67, 6092-6099. [CrossRef] [PubMed]

4. Wang, B.; Hsu, S.H.; Majumder, S.; Kutay, H.; Huang, W.; Jacob, S.T.; Ghoshal, K. TGFbeta-mediated upregulation of hepatic miR-181b promotes hepatocarcinogenesis by targeting TIMP3. Oncogene 2010, 29, 1787-1797. [CrossRef] [PubMed]

5. Wong, C.M.; Wong, C.C.; Lee, J.M.; Fan, D.N.; Au, S.L.; Ng, I.O. Sequential alterations of microRNA expression in hepatocellular carcinoma development and venous metastasis. Hepatology 2012, 55, 1453-1461. [CrossRef] [PubMed]

6. Tsai, W.C.; Hsu, P.W.; Lai, T.C.; Chau, G.Y.; Lin, C.W.; Chen, C.M.; Lin, C.D.; Liao, Y.L.; Wang, J.L.; Chau, Y.P.; et al. MicroRNA-122, a tumor suppressor microRNA that regulates intrahepatic metastasis of hepatocellular carcinoma. Hepatology 2009, 49, 1571-1582. [CrossRef] [PubMed]

7. Fang, J.H.; Zhou, H.C.; Zeng, C.; Yang, J.; Liu, Y.; Huang, X.; Zhang, J.P.; Guan, X.Y.; Zhuang, S.M. MicroRNA-29b suppresses tumor angiogenesis, invasion, and metastasis by regulating matrix metalloproteinase 2 expression. Hepatology 2011, 54, 1729-1740. [CrossRef]

8. Yao, J.; Liang, L.; Huang, S.; Ding, J.; Tan, N.; Zhao, Y.; Yan, M.; Ge, C.; Zhang, Z.; Chen, T.; et al. MicroRNA-30d promotes tumor invasion and metastasis by targeting Galphai2 in hepatocellular carcinoma. Hepatology 2010, 51, 846-856. [CrossRef]

9. Gramantieri, L.; Fornari, F.; Ferracin, M.; Veronese, A.; Sabbioni, S.; Calin, G.A.; Grazi, G.L.; Croce, C.M.; Bolondi, L.; Negrini, M. MicroRNA-221 targets Bmf in hepatocellular carcinoma and correlates with tumor multifocality. Clin. Cancer Res. 2009, 15, 5073-5081. [CrossRef]

10. Fornari, F.; Gramantieri, L.; Ferracin, M.; Veronese, A.; Sabbioni, S.; Calin, G.A.; Grazi, G.L.; Giovannini, C.; Croce, C.M.; Bolondi, L.; et al. miR-221 controls CDKN1C/p57 and CDKN1B/p27 expression in human hepatocellular carcinoma. Oncogene 2008, 27, 5651-5661. [CrossRef]

11. Fornari, F.; Milazzo, M.; Chieco, P.; Negrini, M.; Calin, G.A.; Grazi, G.L.; Pollutri, D.; Croce, C.M.; Bolondi, L.; Gramantieri, L. miR-199a-3p regulates mTOR and c-Met to influence the doxorubicin sensitivity of human hepatocarcinoma cells. Cancer Res. 2010, 70, 5184-5193. [CrossRef] [PubMed]

12. Pineau, P.; Volinia, S.; McJunkin, K.; Marchio, A.; Battiston, C.; Terris, B.; Mazzaferro, V.; Lowe, S.W.; Croce, C.M.; Dejean, A. miR-221 overexpression contributes to liver tumorigenesis. Proc. Natl. Acad. Sci. USA 2010, 107, 264-269. [CrossRef] [PubMed]

13. Budhu, A.; Jia, H.L.; Forgues, M.; Liu, C.G.; Goldstein, D.; Lam, A.; Zanetti, K.A.; Ye, Q.H.; Qin, L.X.; Croce, C.M.; et al. Identification of metastasis-related microRNAs in hepatocellular carcinoma. Hepatology 2008, 47, 897-907. [CrossRef] [PubMed]

14. Garofalo, M.; Di Leva, G.; Romano, G.; Nuovo, G.; Suh, S.S.; Ngankeu, A.; Taccioli, C.; Pichiorri, F.; Alder, H.; Secchiero, P.; et al. miR-221\&222 regulate TRAIL resistance and enhance tumorigenicity through PTEN and TIMP3 downregulation. Cancer Cell 2009, 16, 498-509.

15. Pollutri, D.; Patrizi, C.; Marinelli, S.; Giovannini, C.; Trombetta, E.; Giannone, F.A.; Baldassarre, M.; Quarta, S.; Vandewynckel, Y.P.; Vandierendonck, A.; et al. The epigenetically regulated miR-494 associates with stem-cell phenotype and induces sorafenib resistance in hepatocellular carcinoma. Cell Death Dis. 2018, 9, e4. [CrossRef]

16. Lim, L.; Balakrishnan, A.; Huskey, N.; Jones, K.D.; Jodari, M.; Ng, R.; Song, G.; Riordan, J.; Anderton, B.; Cheung, S.T.; et al. MicroRNA-494 within an oncogenic microRNA megacluster regulates G1/S transition in liver tumorigenesis through suppression of mutated in colorectal cancer. Hepatology 2014, 59, $202-215$. [CrossRef] 
17. Cheng, L.; Zhu, Y.; Han, H.; Zhang, Q.; Cui, K.; Shen, H.; Zhang, J.; Yan, J.; Prochownik, E.; Li, Y. MicroRNA-148a deficiency promotes hepatic lipid metabolism and hepatocarcinogenesis in mice. Cell Death Dis. 2017, 8, e2916. [CrossRef]

18. Callegari, E.; Elamin, B.K.; Giannone, F.; Milazzo, M.; Altavilla, G.; Fornari, F.; Giacomelli, L.; D'Abundo, L.; Ferracin, M.; Bassi, C.; et al. Liver tumorigenicity promoted by microRNA-221 in a mouse transgenic model. Hepatology 2012, 56, 1025-1033. [CrossRef]

19. Callegari, E.; D’Abundo, L.; Guerriero, P.; Simioni, C.; Elamin, B.K.; Russo, M.; Cani, A.; Bassi, C.; Zagatti, B.; Giacomelli, L.; et al. miR-199a-3p Modulates MTOR and PAK4 Pathways and Inhibits Tumor Growth in a Hepatocellular Carcinoma Transgenic Mouse Model. Mol. Ther. Nucleic Acids 2018, 11, 485-493. [CrossRef]

20. Callegari, E.; Domenicali, M.; Shankaraiah, R.C.; D'Abundo, L.; Guerriero, P.; Giannone, F.; Baldassarre, M.; Bassi, C.; Elamin, B.K.; Zagatti, B.; et al. MicroRNA-Based Prophylaxis in a Mouse Model of Cirrhosis and Liver Cancer. Mol. Ther. Nucleic Acids 2019, 14, 239-250. [CrossRef]

21. Wu, H.; Tao, J.; Li, X.; Zhang, T.; Zhao, L.; Wang, Y.; Zhang, L.; Xiong, J.; Zeng, Z.; Zhan, N.; et al. MicroRNA-206 prevents the pathogenesis of hepatocellular carcinoma by modulating expression of met proto-oncogene and cyclin-dependent kinase 6 in mice. Hepatology 2017, 66, 1952-1967. [CrossRef] [PubMed]

22. Gougelet, A.; Sartor, C.; Bachelot, L.; Godard, C.; Marchiol, C.; Renault, G.; Tores, F.; Nitschke, P.; Cavard, C.; Terris, B.; et al. Antitumour activity of an inhibitor of miR-34a in liver cancer with beta-catenin-mutations. Gut 2016, 65, 1024-1034. [CrossRef] [PubMed]

23. He, C.; Dong, X.; Zhai, B.; Jiang, X.; Dong, D.; Li, B.; Jiang, H.; Xu, S.; Sun, X. miR-21 mediates sorafenib resistance of hepatocellular carcinoma cells by inhibiting autophagy via the PTEN/Akt pathway. Oncotarget 2015, 6, 28867-28881. [CrossRef] [PubMed]

24. Xue, H.Y.; Liu, Y.; Liao, J.Z.; Lin, J.S.; Li, B.; Yuan, W.G.; Lee, R.J.; Li, L.; Xu, C.R.; He, X.X. Gold nanoparticles delivered miR-375 for treatment of hepatocellular carcinoma. Oncotarget 2016, 7, 86675-86686. [CrossRef]

25. Jilek, J.L.; Zhang, Q.Y.; Tu, M.J.; Ho, P.Y.; Duan, Z.; Qiu, J.X.; Yu, A.M. Bioengineered Let-7c Inhibits Orthotopic Hepatocellular Carcinoma and Improves Overall Survival with Minimal Immunogenicity. Mol. Ther. Nucleic Acids 2019, 14, 498-508. [CrossRef]

26. Kota, J.; Chivukula, R.R.; O’Donnell, K.A.; Wentzel, E.A.; Montgomery, C.L.; Hwang, H.W.; Chang, T.C.; Vivekanandan, P.; Torbenson, M.; Clark, K.R.; et al. Therapeutic microRNA delivery suppresses tumorigenesis in a murine liver cancer model. Cell 2009, 137, 1005-1017. [CrossRef]

27. Jin, F.; Wang, Y.; Li, M.; Zhu, Y.; Liang, H.; Wang, C.; Wang, F.; Zhang, C.Y.; Zen, K.; Li, L. miR-26 enhances chemosensitivity and promotes apoptosis of hepatocellular carcinoma cells through inhibiting autophagy. Cell Death Dis. 2017, 8, e2540. [CrossRef] [PubMed]

28. Xue, R.; Li, R.; Guo, H.; Guo, L.; Su, Z.; Ni, X.; Qi, L.; Zhang, T.; Li, Q.; Zhang, Z.; et al. Variable Intra-Tumor Genomic Heterogeneity of Multiple Lesions in Patients With Hepatocellular Carcinoma. Gastroenterology 2016, 150, 998-1008. [CrossRef]

29. He, L.; Tian, D.A.; Li, P.Y.; He, X.X. Mouse models of liver cancer: Progress and recommendations. Oncotarget 2015, 6, 23306-23322. [CrossRef]

30. Sekine, S.; Ogawa, R.; Ito, R.; Hiraoka, N.; McManus, M.T.; Kanai, Y.; Hebrok, M. Disruption of Dicer1 induces dysregulated fetal gene expression and promotes hepatocarcinogenesis. Gastroenterology 2009, 136, 2304-2315. [CrossRef]

31. Hand, N.J.; Master, Z.R.; Le Lay, J.; Friedman, J.R. Hepatic function is preserved in the absence of mature microRNAs. Hepatology 2009, 49, 618-626. [CrossRef] [PubMed]

32. Krutzfeldt, J.; Rajewsky, N.; Braich, R.; Rajeev, K.G.; Tuschl, T.; Manoharan, M.; Stoffel, M. Silencing of microRNAs in vivo with 'antagomirs'. Nature 2005, 438, 685-689. [CrossRef] [PubMed]

33. Esau, C.; Davis, S.; Murray, S.F.; Yu, X.X.; Pandey, S.K.; Pear, M.; Watts, L.; Booten, S.L.; Graham, M.; McKay, R.; et al. miR-122 regulation of lipid metabolism revealed by in vivo antisense targeting. Cell Metab. 2006, 3, 87-98. [CrossRef] [PubMed]

34. Kitagawa, N.; Ojima, H.; Shirakihara, T.; Shimizu, H.; Kokubu, A.; Urushidate, T.; Totoki, Y.; Kosuge, T.; Miyagawa, S.; Shibata, T. Downregulation of the microRNA biogenesis components and its association with poor prognosis in hepatocellular carcinoma. Cancer Sci. 2013, 104, 543-551. [CrossRef] [PubMed]

35. Jopling, C.L.; Yi, M.; Lancaster, A.M.; Lemon, S.M.; Sarnow, P. Modulation of hepatitis C virus RNA abundance by a liver-specific MicroRNA. Science 2005, 309, 1577-1581. [CrossRef] [PubMed] 
36. Hsu, S.H.; Wang, B.; Kota, J.; Yu, J.; Costinean, S.; Kutay, H.; Yu, L.; Bai, S.; La Perle, K.; Chivukula, R.R.; et al. Essential metabolic, anti-inflammatory, and anti-tumorigenic functions of miR-122 in liver. J. Clin. Investig. 2012, 122, 2871-2883. [CrossRef] [PubMed]

37. Tsai, W.C.; Hsu, S.D.; Hsu, C.S.; Lai, T.C.; Chen, S.J.; Shen, R.; Huang, Y.; Chen, H.C.; Lee, C.H.; Tsai, T.F.; et al. MicroRNA-122 plays a critical role in liver homeostasis and hepatocarcinogenesis. J. Clin. Investig. 2012, 122, 2884-2897. [CrossRef]

38. Hsu, S.D.; Huang, H.Y.; Chou, C.H.; Sun, Y.M.; Hsu, M.T.; Tsou, A.P. Integrated analyses to reconstruct microRNA-mediated regulatory networks in mouse liver using high-throughput profiling. BMC Genom. 2015, 16, e2. [CrossRef]

39. Valdmanis, P.N.; Kim, H.K.; Chu, K.; Zhang, F.; Xu, J.; Munding, E.M.; Shen, J.; Kay, M.A. miR-122 removal in the liver activates imprinted microRNAs and enables more effective microRNA-mediated gene repression. Nat. Commun. 2018, 9, e5321. [CrossRef]

40. Luk, J.M.; Burchard, J.; Zhang, C.; Liu, A.M.; Wong, K.F.; Shek, F.H.; Lee, N.P.; Fan, S.T.; Poon, R.T.; Ivanovska, I.; et al. DLK1-DIO3 genomic imprinted microRNA cluster at 14q32.2 defines a stemlike subtype of hepatocellular carcinoma associated with poor survival. J. Biol. Chem. 2011, 286, 30706-30713. [CrossRef]

41. Veronese, A.; Lupini, L.; Consiglio, J.; Visone, R.; Ferracin, M.; Fornari, F.; Zanesi, N.; Alder, H.; D’Elia, G.; Gramantieri, L.; et al. Oncogenic role of miR-483-3p at the IGF2/483 locus. Cancer Res. 2010, 70, 3140-3149. [CrossRef] [PubMed]

42. Gailhouste, L.; Gomez-Santos, L.; Hagiwara, K.; Hatada, I.; Kitagawa, N.; Kawaharada, K.; Thirion, M.; Kosaka, N.; Takahashi, R.U.; Shibata, T.; et al. miR-148a plays a pivotal role in the liver by promoting the hepatospecific phenotype and suppressing the invasiveness of transformed cells. Hepatology 2013, 58, 1153-1165. [CrossRef] [PubMed]

43. He, Y.; Hwang, S.; Cai, Y.; Kim, S.J.; Xu, M.; Yang, D.; Guillot, A.; Feng, D.; Seo, W.; Hou, X.; et al. MicroRNA-223 Ameliorates Nonalcoholic Steatohepatitis and Cancer by Targeting Multiple Inflammatory and Oncogenic Genes in Hepatocytes. Hepatology 2019, 70, 1150-1167. [CrossRef] [PubMed]

44. Dong, Y.W.; Wang, R.; Cai, Q.Q.; Qi, B.; Wu, W.; Zhang, Y.H.; Wu, X.Z. Sulfatide epigenetically regulates miR-223 and promotes the migration of human hepatocellular carcinoma cells. J. Hepatol. 2014, 60, 792-801. [CrossRef] [PubMed]

45. Murakami, Y.; Yasuda, T.; Saigo, K.; Urashima, T.; Toyoda, H.; Okanoue, T.; Shimotohno, K. Comprehensive analysis of microRNA expression patterns in hepatocellular carcinoma and non-tumorous tissues. Oncogene 2006, 25, 2537-2545. [CrossRef] [PubMed]

46. Hou, J.; Lin, L.; Zhou, W.; Wang, Z.; Ding, G.; Dong, Q.; Qin, L.; Wu, X.; Zheng, Y.; Yang, Y.; et al. Identification of miRNomes in human liver and hepatocellular carcinoma reveals miR-199a/b-3p as therapeutic target for hepatocellular carcinoma. Cancer Cell 2011, 19, 232-243. [CrossRef]

47. Giovannini, C.; Fornari, F.; Dallo, R.; Gagliardi, M.; Nipoti, E.; Vasuri, F.; Coada, C.A.; Ravaioli, M.; Bolondi, L.; Gramantieri, L. miR-199-3p replacement affects E-cadherin expression through Notch1 targeting in hepatocellular carcinoma. Acta Histochem. 2018, 120, 95-102. [CrossRef]

48. Starley, B.Q.; Calcagno, C.J.; Harrison, S.A. Nonalcoholic fatty liver disease and hepatocellular carcinoma: A weighty connection. Hepatology 2010, 51, 1820-1832. [CrossRef]

49. Domenicali, M.; Caraceni, P.; Giannone, F.; Baldassarre, M.; Lucchetti, G.; Quarta, C.; Patti, C.; Catani, L.; Nanni, C.; Lemoli, R.M.; et al. A novel model of CCl4-induced cirrhosis with ascites in the mouse. J. Hepatol. 2009, 51, 991-999. [CrossRef]

50. Hayashita, Y.; Osada, H.; Tatematsu, Y.; Yamada, H.; Yanagisawa, K.; Tomida, S.; Yatabe, Y.; Kawahara, K.; Sekido, Y.; Takahashi, T. A polycistronic microRNA cluster, miR-17-92, is overexpressed in human lung cancers and enhances cell proliferation. Cancer Res. 2005, 65, 9628-9632. [CrossRef]

51. He, L.; Thomson, J.M.; Hemann, M.T.; Hernando-Monge, E.; Mu, D.; Goodson, S.; Powers, S.; Cordon-Cardo, C.; Lowe, S.W.; Hannon, G.J.; et al. A microRNA polycistron as a potential human oncogene. Nature 2005, 435, 828-833. [CrossRef] [PubMed]

52. O'Donnell, K.A.; Wentzel, E.A.; Zeller, K.I.; Dang, C.V.; Mendell, J.T. c-Myc-regulated microRNAs modulate E2F1 expression. Nature 2005, 435, 839-843. [CrossRef] [PubMed]

53. Li, Y.; Choi, P.S.; Casey, S.C.; Dill, D.L.; Felsher, D.W. MYC through miR-17-92 suppresses specific target genes to maintain survival, autonomous proliferation, and a neoplastic state. Cancer Cell 2014, 26, 262-272. [CrossRef] [PubMed] 
54. Zhu, H.; Han, C.; Wu, T. miR-17-92 cluster promotes hepatocarcinogenesis. Carcinogenesis 2015, 36, 1213-1222. [CrossRef]

55. Lan, S.H.; Wu, S.Y.; Zuchini, R.; Lin, X.Z.; Su, I.J.; Tsai, T.F.; Lin, Y.J.; Wu, C.T.; Liu, H.S. Autophagy suppresses tumorigenesis of hepatitis B virus-associated hepatocellular carcinoma through degradation of microRNA-224. Hepatology 2014, 59, 505-517. [CrossRef]

56. Kim, C.M.; Koike, K.; Saito, I.; Miyamura, T.; Jay, G. HBx gene of hepatitis B virus induces liver cancer in transgenic mice. Nature 1991, 351, 317-320. [CrossRef]

57. Wang, Y.; Ren, J.; Gao, Y.; Ma, J.Z.; Toh, H.C.; Chow, P.; Chung, A.Y.; Ooi, L.L.; Lee, C.G. MicroRNA-224 targets SMAD family member 4 to promote cell proliferation and negatively influence patient survival. PLOS ONE 2013, 8, e68744. [CrossRef]

58. Gao, P.; Wong, C.C.; Tung, E.K.; Lee, J.M.; Wong, C.M.; Ng, I.O. Deregulation of microRNA expression occurs early and accumulates in early stages of HBV-associated multistep hepatocarcinogenesis. J. Hepatol. 2011, 54, 1177-1184. [CrossRef]

59. Tang, Q.; Wang, Q.; Zhang, Q.; Lin, S.Y.; Zhu, Y.; Yang, X.; Guo, A.Y. Gene expression, regulation of DEN and HBx induced HCC mice models and comparisons of tumor, para-tumor and normal tissues. BMC Cancer 2017, 17, e862. [CrossRef]

60. Calvisi, D.F.; Ladu, S.; Gorden, A.; Farina, M.; Conner, E.A.; Lee, J.S.; Factor, V.M.; Thorgeirsson, S.S. Ubiquitous activation of Ras and Jak/Stat pathways in human HCC. Gastroenterology 2006, 130, 1117-1128. [CrossRef]

61. Gerard, C.; Di-Luoffo, M.; Gonay, L.; Caruso, S.; Couchy, G.; Loriot, A.; Castven, D.; Tao, J.; Konobrocka, K.; Cordi, S.; et al. Dynamics and predicted drug response of a gene network linking dedifferentiation with beta-catenin dysfunction in hepatocellular carcinoma. J. Hepatol. 2019, 71, 323-332. [CrossRef] [PubMed]

62. Elmen, J.; Lindow, M.; Schutz, S.; Lawrence, M.; Petri, A.; Obad, S.; Lindholm, M.; Hedtjarn, M.; Hansen, H.F.; Berger, U.; et al. LNA-mediated microRNA silencing in non-human primates. Nature 2008, 452, 896-899. [CrossRef] [PubMed]

63. Chen, C.Z. MicroRNAs as oncogenes and tumor suppressors. N. Engl. J. Med. 2005, 353, $1768-1771$. [CrossRef] [PubMed]

64. Fornari, F.; Milazzo, M.; Chieco, P.; Negrini, M.; Marasco, E.; Capranico, G.; Mantovani, V.; Marinello, J.; Sabbioni, S.; Callegari, E.; et al. In hepatocellular carcinoma miR-519d is up-regulated by p53 and DNA hypomethylation and targets CDKN1A/p21, PTEN, AKT3 and TIMP2. J. Pathol. 2012, 227, 275-285. [CrossRef]

65. Fornari, F.; Milazzo, M.; Galassi, M.; Callegari, E.; Veronese, A.; Miyaaki, H.; Sabbioni, S.; Mantovani, V.; Marasco, E.; Chieco, P.; et al. p53/mdm2 feedback loop sustains miR-221 expression and dictates the response to anticancer treatments in hepatocellular carcinoma. Mol. Cancer Res. 2014, 12, 203-216. [CrossRef]

66. Beg, M.S.; Brenner, A.J.; Sachdev, J.; Borad, M.; Kang, Y.K.; Stoudemire, J.; Smith, S.; Bader, A.G.; Kim, S.; Hong, D.S. Phase I study of MRX34, a liposomal miR-34a mimic, administered twice weekly in patients with advanced solid tumors. Investig. New Drugs 2017, 35, 180-188. [CrossRef]

67. Zhai, B.; Hu, F.; Jiang, X.; Xu, J.; Zhao, D.; Liu, B.; Pan, S.; Dong, X.; Tan, G.; Wei, Z.; et al. Inhibition of Akt reverses the acquired resistance to sorafenib by switching protective autophagy to autophagic cell death in hepatocellular carcinoma. Mol. Cancer Ther. 2014, 13, 1589-1598. [CrossRef]

68. Tang, S.; Tan, G.; Jiang, X.; Han, P.; Zhai, B.; Dong, X.; Qiao, H.; Jiang, H.; Sun, X. An artificial lncRNA targeting multiple miRNAs overcomes sorafenib resistance in hepatocellular carcinoma cells. Oncotarget 2016, 7, 73257-73269. [CrossRef]

69. Li, X.; Su, Y.; Sun, B.; Ji, W.; Peng, Z.; Xu, Y.; Wu, M.; Su, C. An Artificially Designed Interfering lncRNA Expressed by Oncolytic Adenovirus Competitively Consumes OncomiRs to Exert Antitumor Efficacy in Hepatocellular Carcinoma. Mol. Cancer Ther. 2016, 15, 1436-1451. [CrossRef]

70. Wang, W.P.; Ho, P.Y.; Chen, Q.X.; Addepalli, B.; Limbach, P.A.; Li, M.M.; Wu, W.J.; Jilek, J.L.; Qiu, J.X.; Zhang, H.J.; et al. Bioengineering Novel Chimeric microRNA-34a for Prodrug Cancer Therapy: High-Yield Expression and Purification, and Structural and Functional Characterization. J. Pharmacol. Exp. Ther. 2015, 354, 131-141. [CrossRef]

71. Gross, C.; Steiger, K.; Sayyed, S.; Heid, I.; Feuchtinger, A.; Walch, A.; Hess, J.; Unger, K.; Zitzelsberger, H.; Settles, M.; et al. Model Matters: Differences in Orthotopic Rat Hepatocellular Carcinoma Physiology Determine Therapy Response to Sorafenib. Clin. Cancer Res. 2015, 21, 4440-4450. [CrossRef] [PubMed] 
72. Verna, L.; Whysner, J.; Williams, G.M. N-nitrosodiethylamine mechanistic data and risk assessment: Bioactivation, DNA-adduct formation, mutagenicity, and tumor initiation. Pharmacol. Ther. 1996, 71, 57-81. [CrossRef]

73. Magee, P.N.; Lee, K.Y. Cellular injury and carcinogenesis. Alkylation of ribonucleic acid of rat liver by diethylnitrosamine and n-butylmethylnitrosamine in vivo. Biochem. J. 1964, 91, 35-42. [CrossRef] [PubMed]

74. Rajewsky, M.F.; Dauber, W.; Frankenberg, H. Liver carcinogenesis by diethylnitrosamine in the rat. Science 1966, 152, 83-85. [CrossRef] [PubMed]

75. Di Stefano, G.; Fiume, L.; Bolondi, L.; Lanza, M.; Pariali, M.; Chieco, P. Enhanced uptake of lactosaminated human albumin by rat hepatocarcinomas: Implications for an improved chemotherapy of primary liver tumors. Liver Int. 2005, 25, 854-860. [CrossRef] [PubMed]

76. Ding, Y.F.; Wu, Z.H.; Wei, Y.J.; Shu, L.; Peng, Y.R. Hepatic inflammation-fibrosis-cancer axis in the rat hepatocellular carcinoma induced by diethylnitrosamine. Cancer Res. Clin. Oncol. 2017, 143, 821-834. [CrossRef] [PubMed]

77. Giovannini, C.; Minguzzi, M.; Baglioni, M.; Fornari, F.; Giannone, F.; Ravaioli, M.; Cescon, M.; Chieco, P.; Bolondi, L.; Gramantieri, L. Suppression of $\mathrm{p} 53$ by Notch3 is mediated by Cyclin G1 and sustained by MDM2 and miR-221 axis in hepatocellular carcinoma. Oncotarget 2014, 5, 10607-10620. [CrossRef]

78. Giovannini, C.; Salzano, A.M.; Baglioni, M.; Vitale, M.; Scaloni, A.; Zambrano, N.; Giannone, F.A.; Vasuri, F.; D'Errico, A.; Svegliati Baroni, G.; et al. Brivanib in combination with Notch3 silencing shows potent activity in tumour models. Br. J. Cancer 2019, 120, 601-611. [CrossRef]

79. Giovannini, C.; Minguzzi, M.; Genovese, F.; Baglioni, M.; Gualandi, A.; Ravaioli, M.; Milazzo, M.; Tavolari, S.; Bolondi, L.; Gramantieri, L. Molecular and proteomic insight into Notch1 characterization in hepatocellular carcinoma. Oncotarget 2016, 7, 39609-39626. [CrossRef]

80. Huang, X.H.; Wang, Q.; Chen, J.S.; Fu, X.H.; Chen, X.L.; Chen, L.Z.; Li, W.; Bi, J.; Zhang, L.J.; $\mathrm{Fu}, \mathrm{Q}$; et al. Bead-based microarray analysis of microRNA expression in hepatocellular carcinoma: miR-338 is downregulated. Hepatol. Res. 2009, 39, 786-794. [CrossRef]

81. Xu, H.; Zhao, L.; Fang, Q.; Sun, J.; Zhang, S.; Zhan, C.; Liu, S.; Zhang, Y. miR-338-3p inhibits hepatocarcinoma cells and sensitizes these cells to sorafenib by targeting hypoxia-induced factor 1alpha. PLoS ONE 2014, 9, e115565. [CrossRef] [PubMed]

82. Nie, H.; Li, J.; Yang, X.M.; Cao, Q.Z.; Feng, M.X.; Xue, F.; Wei, L.; Qin, W.; Gu, J.; Xia, Q.; et al. Mineralocorticoid receptor suppresses cancer progression and the Warburg effect by modulating the miR-338-3p-PKLR axis in hepatocellular carcinoma. Hepatology 2015, 62, 1145-1159. [CrossRef] [PubMed]

83. Lan, Y.; Han, J.; Wang, Y.; Wang, J.; Yang, G.; Li, K.; Song, R.; Zheng, T.; Liang, Y.; Pan, S.; et al. STK17B promotes carcinogenesis and metastasis via AKT/GSK-3beta/Snail signaling in hepatocellular carcinoma. Cell Death Dis. 2018, 9, e236. [CrossRef] [PubMed]

84. Yu, M.; Lin, Y.; Zhou, Y.; Jin, H.; Hou, B.; Wu, Z.; Li, Z.; Jian, Z.; Sun, J. miR-144 suppresses cell proliferation, migration, and invasion in hepatocellular carcinoma by targeting SMAD4. Onco Targets Ther. 2016, 9, 4705-4714. [CrossRef] [PubMed]

85. Gu, J.; Liu, X.; Li, J.; He, Y. MicroRNA-144 inhibits cell proliferation, migration and invasion in human hepatocellular carcinoma by targeting CCNB1. Cancer Cell Int. 2019, 19, e15. [CrossRef]

86. Cartier, F.; Indersie, E.; Lesjean, S.; Charpentier, J.; Hooks, K.B.; Ghousein, A.; Desplat, A.; Dugot-Senant, N.; Trezeguet, V.; Sagliocco, F.; et al. New tumor suppressor microRNAs target glypican-3 in human liver cancer. Oncotarget 2017, 8, 41211-41226. [CrossRef]

87. Liao, C.G.; Kong, L.M.; Zhou, P.; Yang, X.L.; Huang, J.G.; Zhang, H.L.; Lu, N. miR-10b is overexpressed in hepatocellular carcinoma and promotes cell proliferation, migration and invasion through RhoC, uPAR and MMPs. J. Transl. Med. 2014, 12, e234. [CrossRef]

88. Zhu, Q.; Gong, L.; Wang, J.; Tu, Q.; Yao, L.; Zhang, J.R.; Han, X.J.; Zhu, S.J.; Wang, S.M.; Li, Y.H.; et al. $\mathrm{miR}-10 \mathrm{~b}$ exerts oncogenic activity in human hepatocellular carcinoma cells by targeting expression of CUB and sushi multiple domains 1 (CSMD1). BMC Cancer 2016, 16, e806. [CrossRef]

89. Ying, Q.; Liang, L.; Guo, W.; Zha, R.; Tian, Q.; Huang, S.; Yao, J.; Ding, J.; Bao, M.; Ge, C.; et al. Hypoxia-inducible microRNA-210 augments the metastatic potential of tumor cells by targeting vacuole membrane protein 1 in hepatocellular carcinoma. Hepatology 2011, 54, 2064-2075. [CrossRef] 
90. Kai, A.K.; Chan, L.K.; Lo, R.C.; Lee, J.M.; Wong, C.C.; Wong, J.C.; Ng, I.O. Down-regulation of TIMP2 by HIF-1alpha/miR-210/HIF-3alpha regulatory feedback circuit enhances cancer metastasis in hepatocellular carcinoma. Hepatology 2016, 64, 473-487. [CrossRef]

91. Shen, H.; Li, W.; Tian, Y.; Xu, P.; Wang, H.; Zhang, J.; Li, Y. Upregulation of miR-362-3p Modulates Proliferation and Anchorage-Independent Growth by Directly Targeting Tob2 in Hepatocellular Carcinoma. J. Cell Biochem. 2015, 116, 1563-1573. [CrossRef] [PubMed]

92. Li, Z.; Hu, Y.; Zeng, Q.; Wang, H.; Yan, J.; Li, H.; Yu, Z. Circular RNA MYLK promotes hepatocellular carcinoma progression by increasing Rab23 expression by sponging miR-362-3p. Cancer Cell Int. 2019, 19, e211. [CrossRef] [PubMed]

93. Zhang, J.; Chong, C.C.; Chen, G.G.; Lai, P.B. A Seven-microRNA Expression Signature Predicts Survival in Hepatocellular Carcinoma. PLoS ONE 2015, 10, e0128628. [CrossRef] [PubMed]

94. Yang, X.; Liu, L.; Zou, H.; Zheng, Y.W.; Wang, K.P. circZFR promotes cell proliferation and migration by regulating miR-511/AKT1 axis in hepatocellular carcinoma. Dig. Liver Dis. 2019, 51, 1446-1455. [CrossRef]

95. Grossi, I.; Arici, B.; Portolani, N.; De Petro, G.; Salvi, A. Clinical and biological significance of miR-23b and miR-193a in human hepatocellular carcinoma. Oncotarget 2017, 8, 6955-6969. [CrossRef]

96. Li, P.; Xiao, Z.; Luo, J.; Zhang, Y.; Lin, L. miR-139-5p, miR-940 and miR-193a-5p inhibit the growth of hepatocellular carcinoma by targeting SPOCK1. J. Cell. Mol. Med. 2019, 23, 2475-2488. [CrossRef]

97. Law, P.T.; Ching, A.K.; Chan, A.W.; Wong, Q.W.; Wong, C.K.; To, K.F.; Wong, N. miR-145 modulates multiple components of the insulin-like growth factor pathway in hepatocellular carcinoma. Carcinogenesis 2012, 33, 1134-1141. [CrossRef]

98. Shi, K.Q.; Lin, Z.; Chen, X.J.; Song, M.; Wang, Y.Q.; Cai, Y.J.; Yang, N.B.; Zheng, M.H.; Dong, J.Z.; Zhang, L.; et al. Hepatocellular carcinoma associated microRNA expression signature: Integrated bioinformatics analysis, experimental validation and clinical significance. Oncotarget 2015, 6, 25093-25108. [CrossRef]

99. Simerzin, A.; Zorde-Khvalevsky, E.; Rivkin, M.; Adar, R.; Zucman-Rossi, J.; Couchy, G.; Roskams, T.; Govaere, O.; Oren, M.; Giladi, H.; et al. The liver-specific microRNA-122*, the complementary strand of microRNA-122, acts as a tumor suppressor by modulating the p53/mouse double minute 2 homolog circuitry. Hepatology 2016, 64, 1623-1636. [CrossRef]

100. Wang, W.; Lin, H.; Zhou, L.; Zhu, Q.; Gao, S.; Xie, H.; Liu, Z.; Xu, Z.; Wei, J.; Huang, X.; et al. MicroRNA-30a-3p inhibits tumor proliferation, invasiveness and metastasis and is downregulated in hepatocellular carcinoma. Eur. J. Surg. Oncol. 2014, 40, 1586-1594. [CrossRef]

101. Su, H.; Yang, J.R.; Xu, T.; Huang, J.; Xu, L.; Yuan, Y.; Zhuang, S.M. MicroRNA-101, down-regulated in hepatocellular carcinoma, promotes apoptosis and suppresses tumorigenicity. Cancer Res. 2009, 69, 1135-1142. [CrossRef] [PubMed]

102. Zhang, Y.; Guo, X.; Xiong, L.; Kong, X.; Xu, Y.; Liu, C.; Zou, L.; Li, Z.; Zhao, J.; Lin, N. MicroRNA-101 suppresses SOX9-dependent tumorigenicity and promotes favorable prognosis of human hepatocellular carcinoma. FEBS Lett. 2012, 586, 4362-4370. [CrossRef] [PubMed]

103. Xu, L.; Beckebaum, S.; Iacob, S.; Wu, G.; Kaiser, G.M.; Radtke, A.; Liu, C.; Kabar, I.; Schmidt, H.H.; Zhang, X.; et al. MicroRNA-101 inhibits human hepatocellular carcinoma progression through EZH2 downregulation and increased cytostatic drug sensitivity. J. Hepatol. 2014, 60, 590-598. [CrossRef] [PubMed]

104. Salvi, A.; Conde, I.; Abeni, E.; Arici, B.; Grossi, I.; Specchia, C.; Portolani, N.; Barlati, S.; De Petro, G. Effects of miR-193a and sorafenib on hepatocellular carcinoma cells. Mol. Cancer 2013, 12, e162. [CrossRef]

105. Ma, P.; Wang, H.; Sun, J.; Liu, H.; Zheng, C.; Zhou, X.; Lu, Z. LINC00152 promotes cell cycle progression in hepatocellular carcinoma via miR-193a/b-3p/CCND1 axis. Cell Cycle 2018, 17, 974-984. [CrossRef]

106. Chen, Z.; Huang, Z.; Ye, Q.; Ming, Y.; Zhang, S.; Zhao, Y.; Liu, L.; Wang, Q.; Cheng, K. Prognostic significance and anti-proliferation effect of microRNA-365 in hepatocellular carcinoma. Int. J. Clin. Exp. Pathol. 2015, 8, 1705-1711.

107. Liu, Y.; Zhang, W.; Liu, S.; Liu, K.; Ji, B.; Wang, Y. miR-365 targets ADAM10 and suppresses the cell growth and metastasis of hepatocellular carcinoma. Oncol. Rep. 2017, 37, 1857-1864. [CrossRef]

108. Jiang, Z.B.; Ma, B.Q.; Liu, S.G.; Li, J.; Yang, G.M.; Hou, Y.B.; Si, R.H.; Gao, P.; Yan, H.T. miR-365 regulates liver cancer stem cells via RAC1 pathway. Mol. Carcinog. 2019, 58, 55-65. [CrossRef]

109. Li, W.; Xie, L.; He, X.; Li, J.; Tu, K.; Wei, L.; Wu, J.; Guo, Y.; Ma, X.; Zhang, P.; et al. Diagnostic and prognostic implications of microRNAs in human hepatocellular carcinoma. Int. J. Cancer 2008, 123, 1616-1622. [CrossRef] 
110. Liang, L.; Wong, C.M.; Ying, Q.; Fan, D.N.; Huang, S.; Ding, J.; Yao, J.; Yan, M.; Li, J.; Yao, M.; et al. MicroRNA-125b suppressesed human liver cancer cell proliferation and metastasis by directly targeting oncogene LIN28B2. Hepatology 2010, 52, 1731-1740. [CrossRef]

111. Alpini, G.; Glaser, S.S.; Zhang, J.P.; Francis, H.; Han, Y.; Gong, J.; Stokes, A.; Francis, T.; Hughart, N.; Hubble, L.; et al. Regulation of placenta growth factor by microRNA-125b in hepatocellular cancer. J. Hepatol. 2011, 55, 1339-1345. [CrossRef] [PubMed]

112. Zhao, A.; Zeng, Q.; Xie, X.; Zhou, J.; Yue, W.; Li, Y.; Pei, X. MicroRNA-125b induces cancer cell apoptosis through suppression of Bcl-2 expression. J. Genet. Genom. 2012, 39, 29-35. [CrossRef] [PubMed]

113. Au, S.L.; Wong, C.C.; Lee, J.M.; Fan, D.N.; Tsang, F.H.; Ng, I.O.; Wong, C.M. Enhancer of zeste homolog 2 epigenetically silences multiple tumor suppressor microRNAs to promote liver cancer metastasis. Hepatology 2012, 56, 622-631. [CrossRef] [PubMed]

114. Bai, S.; Nasser, M.W.; Wang, B.; Hsu, S.H.; Datta, J.; Kutay, H.; Yadav, A.; Nuovo, G.; Kumar, P.; Ghoshal, K. MicroRNA-122 inhibits tumorigenic properties of hepatocellular carcinoma cells and sensitizes these cells to sorafenib. J. Biol. Chem. 2009, 284, 32015-32027. [CrossRef]

115. Zhang, Q.Y.; Men, C.J.; Ding, X.W. Upregulation of microRNA-140-3p inhibits epithelial-mesenchymal transition, invasion, and metastasis of hepatocellular carcinoma through inactivation of the MAPK signaling pathway by targeting GRN. J. Cell. Biochem. 2019, 120, 14885-14898. [CrossRef] [PubMed]

116. Yan, Y.; Luo, Y.C.; Wan, H.Y.; Wang, J.; Zhang, P.P.; Liu, M.; Li, X.; Li, S.; Tang, H. MicroRNA-10a is involved in the metastatic process by regulating Eph tyrosine kinase receptor A4-mediated epithelial-mesenchymal transition and adhesion in hepatoma cells. Hepatology 2013, 57, 667-677. [CrossRef]

117. Wu, Y.; Zhou, Y.; Huan, L.; Xu, L.; Shen, M.; Huang, S.; Liang, L. LncRNA MIR22HG inhibits growth, migration and invasion through regulating the miR-10a-5p/NCOR2 axis in hepatocellular carcinoma cells. Cancer Sci. 2019, 110, 973-984. [CrossRef]

118. Zhang, J.; Yang, Y.; Yang, T.; Liu, Y.; Li, A.; Fu, S.; Wu, M.; Pan, Z.; Zhou, W. microRNA-22, downregulated in hepatocellular carcinoma and correlated with prognosis, suppresses cell proliferation and tumourigenicity. Br. J. Cancer 2010, 103, 1215-1220. [CrossRef]

119. Chen, M.; Hu, W.; Xiong, C.L.; Qu, Z.; Yin, C.Q.; Wang, Y.H.; Luo, C.L.; Guan, Q.; Yuan, C.H.; Wang, F.B. miR-22 targets YWHAZ to inhibit metastasis of hepatocellular carcinoma and its down-regulation predicts a poor survival. Oncotarget 2016, 7, 80751-80764. [CrossRef]

120. Luo, L.J.; Zhang, L.P.; Duan, C.Y.; Wang, B.; He, N.N.; Abulimiti, P.; Lin, Y. The inhibition role of miR-22 in hepatocellular carcinoma cell migration and invasion via targeting CD147. Cancer Cell Int. 2017, 17, e17. [CrossRef]

121. Zhu, Y.; Lu, Y.; Zhang, Q.; Liu, J.J.; Li, T.J.; Yang, J.R.; Zeng, C.; Zhuang, S.M. MicroRNA-26a/b and their host genes cooperate to inhibit the G1/S transition by activating the pRb protein. Nucleic Acids Res. 2012, 40, 4615-4625. [CrossRef] [PubMed]

122. Shen, G.; Lin, Y.; Yang, X.; Zhang, J.; Xu, Z.; Jia, H. MicroRNA-26b inhibits epithelial-mesenchymal transition in hepatocellular carcinoma by targeting USP9X. BMC Cancer 2014, 14, e393. [CrossRef] [PubMed]

123. Wang, Y.; Sun, B.; Zhao, X.; Zhao, N.; Sun, R.; Zhu, D.; Zhang, Y.; Li, Y.; Gu, Q.; Dong, X.; et al. Twist1-related miR-26b-5p suppresses epithelial-mesenchymal transition, migration and invasion by targeting SMAD1 in hepatocellular carcinoma. Oncotarget 2016, 7, 24383-24401. [CrossRef] [PubMed]

124. Yang, X.; Liang, L.; Zhang, X.F.; Jia, H.L.; Qin, Y.; Zhu, X.C.; Gao, X.M.; Qiao, P.; Zheng, Y.; Sheng, Y.Y.; et al. MicroRNA-26a suppresses tumor growth and metastasis of human hepatocellular carcinoma by targeting interleukin-6-Stat3 pathway. Hepatology 2013, 58, 158-170. [CrossRef]

125. Yang, X.; Zhang, X.F.; Lu, X.; Jia, H.L.; Liang, L.; Dong, Q.Z.; Ye, Q.H.; Qin, L.X. MicroRNA-26a suppresses angiogenesis in human hepatocellular carcinoma by targeting hepatocyte growth factor-cMet pathway. Hepatology 2014, 59, 1874-1885. [CrossRef]

126. Zhang, X.; Cheng, S.L.; Bian, K.; Wang, L.; Zhang, X.; Yan, B.; Jia, L.T.; Zhao, J.; Gammoh, N.; Yang, A.G.; et al. MicroRNA-26a promotes anoikis in human hepatocellular carcinoma cells by targeting alpha5 integrin. Oncotarget 2015, 6, 2277-2289. [CrossRef]

127. Li, D.; Liu, X.; Lin, L.; Hou, J.; Li, N.; Wang, C.; Wang, P.; Zhang, Q.; Zhang, P.; Zhou, W.; et al. MicroRNA-99a inhibits hepatocellular carcinoma growth and correlates with prognosis of patients with hepatocellular carcinoma. J. Biol. Chem. 2011, 286, 36677-36685. [CrossRef] 
128. Petrelli, A.; Perra, A.; Schernhuber, K.; Cargnelutti, M.; Salvi, A.; Migliore, C.; Ghiso, E.; Benetti, A.; Barlati, S.; Ledda-Columbano, G.M.; et al. Sequential analysis of multistage hepatocarcinogenesis reveals that miR-100 and PLK1 dysregulation is an early event maintained along tumor progression. Oncogene 2012, 31, 4517-4526. [CrossRef]

129. Zhang, J.; Jin, H.; Liu, H.; Lv, S.; Wang, B.; Wang, R.; Liu, H.; Ding, M.; Yang, Y.; Li, L.; et al. miRNA-99a directly regulates AGO2 through translational repression in hepatocellular carcinoma. Oncogenesis 2014, 3, e97. [CrossRef]

130. Li, H.P.; Zeng, X.C.; Zhang, B.; Long, J.T.; Zhou, B.; Tan, G.S.; Zeng, W.X.; Chen, W.; Yang, J.Y. miR-451 inhibits cell proliferation in human hepatocellular carcinoma through direct suppression of IKK-beta. Carcinogenesis 2013, 34, 2443-2451. [CrossRef]

131. Lv, G.; Hu, Z.; Tie, Y.; Du, J.; Fu, H.; Gao, X.; Zheng, X. MicroRNA-451 regulates activating transcription factor 2 expression and inhibits liver cancer cell migration. Oncol. Rep. 2014, 32, 1021-1028. [CrossRef]

132. Huang, J.Y.; Zhang, K.; Chen, D.Q.; Chen, J.; Feng, B.; Song, H.; Chen, Y.; Zhu, Z.; Lu, L.; De, W.; et al. MicroRNA-451: Epithelial-mesenchymal transition inhibitor and prognostic biomarker of hepatocelluar carcinoma. Oncotarget 2015, 6, 18613-18630. [CrossRef] [PubMed]

133. Wei, G.Y.; Hu, M.; Zhao, L.; Guo, W.S. miR-451a suppresses cell proliferation, metastasis and EMT via targeting YWHAZ in hepatocellular carcinoma. Eur. Rev. Med. Pharmacol. Sci. 2019, 23, 5158-5167. [PubMed]

134. Deng, L.; Tang, J.; Yang, H.; Cheng, C.; Lu, S.; Jiang, R.; Sun, B. MTA1 modulated by miR-30e contributes to epithelial-to-mesenchymal transition in hepatocellular carcinoma through an ErbB2-dependent pathway. Oncogene 2017, 36, 3976-3985. [CrossRef] [PubMed]

135. Yang, Y.M.; Lee, W.H.; Lee, C.G.; An, J.; Kim, E.S.; Kim, S.H.; Lee, S.K.; Lee, C.H.; Dhanasekaran, D.N.; Moon, A.; et al. Galpha12 gep oncogene deregulation of p53-responsive microRNAs promotes epithelial-mesenchymal transition of hepatocellular carcinoma. Oncogene 2015, 34, 2910-2921. [CrossRef] [PubMed]

136. Lian, J.; Jing, Y.; Dong, Q.; Huan, L.; Chen, D.; Bao, C.; Wang, Q.; Zhao, F.; Li, J.; Yao, M.; et al. miR-192, a prognostic indicator, targets the SLC39A6/SNAIL pathway to reduce tumor metastasis in human hepatocellular carcinoma. Oncotarget 2016, 7, 2672-2683. [CrossRef] [PubMed]

137. Ge, Y.; Yan, X.; Jin, Y.; Yang, X.; Yu, X.; Zhou, L.; Han, S.; Yuan, Q.; Yang, M. miRNA-192 [corrected] and miRNA-204 Directly Suppress lncRNA HOTTIP and Interrupt GLS1-Mediated Glutaminolysis in Hepatocellular Carcinoma. PLoS Genet. 2015, 11, e1005726. [CrossRef]

138. Yang, H.; Fang, F.; Chang, R.; Yang, L. MicroRNA-140-5p suppresses tumor growth and metastasis by targeting transforming growth factor beta receptor 1 and fibroblast growth factor 9 in hepatocellular carcinoma. Hepatology 2013, 58, 205-217. [CrossRef]

139. Yan, X.; Zhu, Z.; Xu, S.; Yang, L.N.; Liao, X.H.; Zheng, M.; Yang, D.; Wang, J.; Chen, D.; Wang, L.; et al. MicroRNA-140-5p inhibits hepatocellular carcinoma by directly targeting the unique isomerase Pin1 to block multiple cancer-driving pathways. Sci. Rep. 2017, 7, e45915. [CrossRef]

140. Li, C.; Zhou, D.; Hong, H.; Yang, S.; Zhang, L.; Li, S.; Hu, P.; Ren, H.; Mei, Z.; Tang, H. TGFbeta1-miR-140-5p axis mediated up-regulation of Flap Endonuclease 1 promotes epithelial-mesenchymal transition in hepatocellular carcinoma. Aging 2019, 11, 5593-5612.

141. Yu, M.; Xue, H.; Wang, Y.; Shen, Q.; Jiang, Q.; Zhang, X.; Li, K.; Jia, M.; Jia, J.; Xu, J.; et al. miR-345 inhibits tumor metastasis and EMT by targeting IRF1-mediated mTOR/STAT3/AKT pathway in hepatocellular carcinoma. Int. J. Oncol. 2017, 50, 975-983. [CrossRef] [PubMed]

142. Zhang, H.; Liu, H.; Bi, H. MicroRNA-345 inhibits hepatocellular carcinoma metastasis by inhibiting YAP1. Oncol. Rep. 2017, 38, 843-849. [CrossRef] [PubMed]

143. Zhuang, H.; Wu, F.; Wei, W.; Dang, Y.; Yang, B.; Ma, X.; Han, F.; Li, Y. Glycine decarboxylase induces autophagy and is downregulated by miRNA-30d-5p in hepatocellular carcinoma. Cell Death Dis. 2019, 10, e192. [CrossRef] [PubMed]

144. Li, C.; Miao, R.; Liu, S.; Wan, Y.; Zhang, S.; Deng, Y.; Bi, J.; Qu, K.; Zhang, J.; Liu, C. Down-regulation of miR-146b-5p by long noncoding RNA MALAT1 in hepatocellular carcinoma promotes cancer growth and metastasis. Oncotarget 2017, 8, 28683-28695. [CrossRef]

145. Li, J.; Fu, H.; Xu, C.; Tie, Y.; Xing, R.; Zhu, J.; Qin, Y.; Sun, Z.; Zheng, X. miR-183 inhibits TGF-beta1-induced apoptosis by downregulation of PDCD4 expression in human hepatocellular carcinoma cells. BMC Cancer 2010, 10, e354. [CrossRef] 
146. Leung, W.K.; He, M.; Chan, A.W.; Law, P.T.; Wong, N. Wnt/beta-Catenin activates miR-183/96/182 expression in hepatocellular carcinoma that promotes cell invasion. Cancer Lett. 2015, 362, 97-105. [CrossRef]

147. Liu, W.H.; Yeh, S.H.; Lu, C.C.; Yu, S.L.; Chen, H.Y.; Lin, C.Y.; Chen, D.S.; Chen, P.J. MicroRNA-18a prevents estrogen receptor-alpha expression, promoting proliferation of hepatocellular carcinoma cells. Gastroenterology 2009, 136, 683-693. [CrossRef]

148. Liu, L.; Cai, X.; Liu, E.; Tian, X.; Tian, C. MicroRNA-18a promotes proliferation and metastasis in hepatocellular carcinoma via targeting KLF4. Oncotarget 2017, 8, 68263-68269. [CrossRef]

149. Sanchez-Mejias, A.; Kwon, J.; Chew, X.H.; Siemens, A.; Sohn, H.S.; Jing, G.; Zhang, B.; Yang, H.; Tay, Y. A novel SOCS5/miR-18/miR-25 axis promotes tumorigenesis in liver cancer. Int. J. Cancer 2019, 144, 311-321. [CrossRef]

150. Wang, J.; Li, J.; Shen, J.; Wang, C.; Yang, L.; Zhang, X. MicroRNA-182 downregulates metastasis suppressor 1 and contributes to metastasis of hepatocellular carcinoma. BMC Cancer 2012, 12, e227. [CrossRef]

151. Shu, H.; Hu, J.; Deng, H. miR-1249-3p accelerates the malignancy phenotype of hepatocellular carcinoma by directly targeting HNRNPK. Mol. Genet. Genom. Med. 2019, 7, e00867. [CrossRef] [PubMed]

152. Liu, A.M.; Yao, T.J.; Wang, W.; Wong, K.F.; Lee, N.P.; Fan, S.T.; Poon, R.T.; Gao, C.; Luk, J.M. Circulating miR-15b and miR-130b in serum as potential markers for detecting hepatocellular carcinoma: A retrospective cohort study. BMJ Open 2012, 2, e000825. [CrossRef] [PubMed]

153. Yang, Y.; Hou, N.; Wang, X.; Wang, L.; Chang, S.; He, K.; Zhao, Z.; Zhao, X.; Song, T.; Huang, C. miR-15b-5p induces endoplasmic reticulum stress and apoptosis in human hepatocellular carcinoma, both in vitro and in vivo, by suppressing Rab1A. Oncotarget 2015, 6, 16227-16238. [CrossRef] [PubMed]

154. Ji, W.B.; Liu, X.; Luo, Y.; Zhang, W.Z. High expression of miR-15b predicts poor prognosis for hepatocellular carcinoma after curative hepatectomy. Oncol. Rep. 2016, 36, 1901-1908. [CrossRef]

155. Huang, H.; Wang, X.; Wang, C.; Zhuo, L.; Luo, S.; Han, S. The miR-93 promotes proliferation by directly targeting PDCD4 in hepatocellular carcinoma. Neoplasma 2017, 64, 770-777. [CrossRef]

156. Fittipaldi, S.; Vasuri, F.; Bonora, S.; Degiovanni, A.; Santandrea, G.; Cucchetti, A.; Gramantieri, L.; Bolondi, L.; D'Errico, A. miRNA Signature of Hepatocellular Carcinoma Vascularization: How the Controls Can Influence the Signature. Dig. Dis. Sci. 2017, 62, 2397-2407. [CrossRef]

157. Li, B.; Huang, P.; Qiu, J.; Liao, Y.; Hong, J.; Yuan, Y. MicroRNA-130a is down-regulated in hepatocellular carcinoma and associates with poor prognosis. Med. Oncol. 2014, 31, e230. [CrossRef]

158. Yau, W.L.; Lam, C.S.; Ng, L.; Chow, A.K.; Chan, S.T.; Chan, J.Y.; Wo, J.Y.; Ng, K.T.; Man, K.; Poon, R.T.; et al. Over-expression of miR-106b promotes cell migration and metastasis in hepatocellular carcinoma by activating epithelial-mesenchymal transition process. PLOS ONE 2013, 8, e57882. [CrossRef]

159. Xu, C.; Shi, L.; Chen, W.; Fang, P.; Li, J.; Jin, L.; Pan, Z.; Pan, C. miR-106b inhibitors sensitize TRAIL-induced apoptosis in hepatocellular carcinoma through increase of death receptor 4. Oncotarget 2017, 8, 41921-41931. [CrossRef]

160. Shi, D.M.; Bian, X.Y.; Qin, C.D.; Wu, W.Z. miR-106b-5p promotes stem cell-like properties of hepatocellular carcinoma cells by targeting PTEN via PI3K/Akt pathway. Onco Targets Ther. 2018, 11, 571-585. [CrossRef]

161. Wang, C.; Wang, X.; Su, Z.; Fei, H.; Liu, X.; Pan, Q. miR-25 promotes hepatocellular carcinoma cell growth, migration and invasion by inhibiting RhoGDI1. Oncotarget 2015, 6, 36231-36244. [CrossRef] [PubMed]

162. Karakatsanis, A.; Papaconstantinou, I.; Gazouli, M.; Lyberopoulou, A.; Polymeneas, G.; Voros, D. Expression of microRNAs, miR-21, miR-31, miR-122, miR-145, miR-146a, miR-200c, miR-221, miR-222, and miR-223 in patients with hepatocellular carcinoma or intrahepatic cholangiocarcinoma and its prognostic significance. Mol. Carcinog. 2013, 52, 297-303. [CrossRef] [PubMed]

163. Kim, H.S.; Lee, K.S.; Bae, H.J.; Eun, J.W.; Shen, Q.; Park, S.J.; Shin, W.C.; Yang, H.D.; Park, M.; Park, W.S.; et al. MicroRNA-31 functions as a tumor suppressor by regulating cell cycle and epithelial-mesenchymal transition regulatory proteins in liver cancer. Oncotarget 2015, 6, 8089-8102. [CrossRef] [PubMed]

164. Xiong, Y.; Fang, J.H.; Yun, J.P.; Yang, J.; Zhang, Y.; Jia, W.H.; Zhuang, S.M. Effects of microRNA-29 on apoptosis, tumorigenicity, and prognosis of hepatocellular carcinoma. Hepatology 2010, 51, 836-845. [CrossRef] [PubMed]

165. Wong, C.C.; Tse, A.P.; Huang, Y.P.; Zhu, Y.T.; Chiu, D.K.; Lai, R.K.; Au, S.L.; Kai, A.K.; Lee, J.M.; Wei, L.L.; et al. Lysyl oxidase-like 2 is critical to tumor microenvironment and metastatic niche formation in hepatocellular carcinoma. Hepatology 2014, 60, 1645-1658. [CrossRef] 
166. Wu, C.; Chen, W.; Fang, M.; Boye, A.; Tao, X.; Xu, Y.; Hou, S.; Yang, Y. Compound Astragalus and Salvia miltiorrhiza extract inhibits hepatocellular carcinoma progression via miR-145/miR-21 mediated Smad3 phosphorylation. J. Ethnopharmacol. 2019, 231, 98-112. [CrossRef]

167. Fornari, F.; Pollutri, D.; Patrizi, C.; La Bella, T.; Marinelli, S.; Casadei Gardini, A.; Marisi, G.; Baron Toaldo, M.; Baglioni, M.; Salvatore, V.; et al. In Hepatocellular Carcinoma miR-221 Modulates Sorafenib Resistance through Inhibition of Caspase-3-Mediated Apoptosis. Clin. Cancer Res. 2017, 23, 3953-3965. [CrossRef]

168. Weber, A.; O'Connor, T.; Heikenwalder, M. Next Generation of Preclinical Liver Cancer Models. Clin. Cancer Res. 2015, 21, 4254-4256. [CrossRef]

169. Marques, T.G.; Chaib, E.; da Fonseca, J.H.; Lourenco, A.C.; Silva, F.D.; Ribeiro, M.A., Jr.; Galvao, F.H.; D'Albuquerque, L.A. Review of experimental models for inducing hepatic cirrhosis by bile duct ligation and carbon tetrachloride injection. Acta Cir. Bras. 2012, 27, 589-594. [CrossRef]

170. Chen, X.B.; Zheng, X.B.; Cai, Z.X.; Lin, X.J.; Xu, M.Q. MicroRNA-203 promotes liver regeneration after partial hepatectomy in cirrhotic rats. J. Surg. Res. 2017, 211, 53-63. [CrossRef]

171. Zheng, X.B.; Chen, X.B.; Xu, L.L.; Zhang, M.; Feng, L.; Yi, P.S.; Tang, J.W.; Xu, M.Q. miR-203 inhibits augmented proliferation and metastasis of hepatocellular carcinoma residual in the promoted regenerating liver. Cancer Sci. 2017, 108, 338-346. [CrossRef] [PubMed]

172. Solt, D.B.; Medline, A.; Farber, E. Rapid emergence of carcinogen-induced hyperplastic lesions in a new model for the sequential analysis of liver carcinogenesis. Am. J. Pathol. 1977, 88, 595-618. [PubMed]

173. Andersen, J.B.; Loi, R.; Perra, A.; Factor, V.M.; Ledda-Columbano, G.M.; Columbano, A.; Thorgeirsson, S.S. Progenitor-derived hepatocellular carcinoma model in the rat. Hepatology 2010, 51, 1401-1409. [CrossRef] [PubMed]

174. Petrelli, A.; Perra, A.; Cora, D.; Sulas, P.; Menegon, S.; Manca, C.; Migliore, C.; Kowalik, M.A.; Ledda-Columbano, G.M.; Giordano, S.; et al. MicroRNA/gene profiling unveils early molecular changes and nuclear factor erythroid related factor 2 (NRF2) activation in a rat model recapitulating human hepatocellular carcinoma (HCC). Hepatology 2014, 59, 228-241. [CrossRef]

175. Singh, A.; Venkannagari, S.; Oh, K.H.; Zhang, Y.Q.; Rohde, J.M.; Liu, L.; Nimmagadda, S.; Sudini, K.; Brimacombe, K.R.; Gajghate, S.; et al. Small Molecule Inhibitor of NRF2 Selectively Intervenes Therapeutic Resistance in KEAP1-Deficient NSCLC Tumors. ACS Chem. Biol. 2016, 11, 3214-3225. [CrossRef]

176. Kowalik, M.A.; Guzzo, G.; Morandi, A.; Perra, A.; Menegon, S.; Masgras, I.; Trevisan, E.; Angioni, M.M.; Fornari, F.; Quagliata, L.; et al. Metabolic reprogramming identifies the most aggressive lesions at early phases of hepatic carcinogenesis. Oncotarget 2016, 7, 32375-32393. [CrossRef]

177. Adebayo Michael, A.O.; Ahsan, N.; Zabala, V.; Francois-Vaughan, H.; Post, S.; Brilliant, K.E.; Salomon, A.R.; Sanders, J.A.; Gruppuso, P.A. Proteomic analysis of laser capture microdissected focal lesions in a rat model of progenitor marker-positive hepatocellular carcinoma. Oncotarget 2017, 8, 26041-26056.

178. Francois-Vaughan, H.; Adebayo, A.O.; Brilliant, K.E.; Parry, N.M.A.; Gruppuso, P.A.; Sanders, J.A. Persistent effect of mTOR inhibition on preneoplastic foci progression and gene expression in a rat model of hepatocellular carcinoma. Carcinogenesis 2016, 37, 408-419. [CrossRef]

179. Boyault, S.; Rickman, D.S.; de Reynies, A.; Balabaud, C.; Rebouissou, S.; Jeannot, E.; Herault, A.; Saric, J.; Belghiti, J.; Franco, D.; et al. Transcriptome classification of HCC is related to gene alterations and to new therapeutic targets. Hepatology 2007, 45, 42-52. [CrossRef]

180. Chiang, D.Y.; Villanueva, A.; Hoshida, Y.; Peix, J.; Newell, P.; Minguez, B.; LeBlanc, A.C.; Donovan, D.J.; Thung, S.N.; Sole, M.; et al. Focal gains of VEGFA and molecular classification of hepatocellular carcinoma. Cancer Res. 2008, 68, 6779-6788. [CrossRef]

181. Guan, D.X.; Shi, J.; Zhang, Y.; Zhao, J.S.; Long, L.Y.; Chen, T.W.; Zhang, E.B.; Feng, Y.Y.; Bao, W.D.; Deng, Y.Z.; et al. Sorafenib enriches epithelial cell adhesion molecule-positive tumor initiating cells and exacerbates a subtype of hepatocellular carcinoma through TSC2-AKT cascade. Hepatology 2015, 62, 1791-1803. [CrossRef] [PubMed]

182. Perra, A.; Kowalik, M.A.; Ghiso, E.; Ledda-Columbano, G.M.; Di Tommaso, L.; Angioni, M.M.; Raschioni, C.; Testore, E.; Roncalli, M.; Giordano, S.; et al. YAP activation is an early event and a potential therapeutic target in liver cancer development. J. Hepatol. 2014, 61, 1088-1096. [CrossRef] [PubMed]

183. Frau, C.; Loi, R.; Petrelli, A.; Perra, A.; Menegon, S.; Kowalik, M.A.; Pinna, S.; Leoni, V.P.; Fornari, F.; Gramantieri, L.; et al. Local hypothyroidism favors the progression of preneoplastic lesions to hepatocellular carcinoma in rats. Hepatology 2015, 61, 249-259. [CrossRef] [PubMed] 
184. Brockhausen, J.; Tay, S.S.; Grzelak, C.A.; Bertolino, P.; Bowen, D.G.; d'Avigdor, W.M.; Teoh, N.; Pok, S.; Shackel, N.; Gamble, J.R.; et al. miR-181a mediates TGF-beta-induced hepatocyte EMT and is dysregulated in cirrhosis and hepatocellular cancer. Liver Int. 2015, 35, 240-253. [CrossRef]

185. Caja, L.; Dituri, F.; Mancarella, S.; Caballero-Diaz, D.; Moustakas, A.; Giannelli, G.; Fabregat, I. TGF-beta and the Tissue Microenvironment: Relevance in Fibrosis and Cancer. Int. J. Mol. Sci. 2018, 19, 1294. [CrossRef]

186. Guo, J.; Ma, Y.; Peng, X.; Jin, H.; Liu, J. LncRNA CCAT1 promotes autophagy via regulating ATG7 by sponging miR-181 in hepatocellular carcinoma. J. Cell. Biochem. 2019, 120, 17975-17983. [CrossRef]

187. Janku, F.; McConkey, D.J.; Hong, D.S.; Kurzrock, R. Autophagy as a target for anticancer therapy. Nat. Rev. Clin. Oncol. 2011, 8, 528-539. [CrossRef]

188. Kowalik, M.A.; Sulas, P.; Ledda-Columbano, G.M.; Giordano, S.; Columbano, A.; Perra, A. Cytokeratin-19 positivity is acquired along cancer progression and does not predict cell origin in rat hepatocarcinogenesis. Oncotarget 2015, 6, 38749-38763. [CrossRef]

189. Mattu, S.; Fornari, F.; Quagliata, L.; Perra, A.; Angioni, M.M.; Petrelli, A.; Menegon, S.; Morandi, A.; Chiarugi, P.; Ledda-Columbano, G.M.; et al. The metabolic gene HAO2 is downregulated in hepatocellular carcinoma and predicts metastasis and poor survival. J. Hepatol. 2016, 64, 891-898. [CrossRef]

190. Zeindl-Eberhart, E.; Haraida, S.; Liebmann, S.; Jungblut, P.R.; Lamer, S.; Mayer, D.; Jager, G.; Chung, S.; Rabes, H.M. Detection and identification of tumor-associated protein variants in human hepatocellular carcinomas. Hepatology 2004, 39, 540-549. [CrossRef]

191. Torres-Mena, J.E.; Salazar-Villegas, K.N.; Sanchez-Rodriguez, R.; Lopez-Gabino, B.; Del Pozo-Yauner, L.; Arellanes-Robledo, J.; Villa-Trevino, S.; Gutierrez-Nava, M.A.; Perez-Carreon, J.I. Aldo-Keto Reductases as Early Biomarkers of Hepatocellular Carcinoma: A Comparison Between Animal Models and Human HCC. Dig. Dis. Sci. 2018, 63, 934-944. [CrossRef] [PubMed]

192. Goessling, W.; Sadler, K.C. Zebrafish: An important tool for liver disease research. Gastroenterology 2015, 149, 1361-1377. [CrossRef] [PubMed]

193. Lam, S.H.; Wu, Y.L.; Vega, V.B.; Miller, L.D.; Spitsbergen, J.; Tong, Y.; Zhan, H.; Govindarajan, K.R.; Lee, S.; Mathavan, S.; et al. Conservation of gene expression signatures between zebrafish and human liver tumors and tumor progression. Nat. Biotechnol. 2006, 24, 73-75. [CrossRef] [PubMed]

194. Zheng, W.; Li, Z.; Nguyen, A.T.; Li, C.; Emelyanov, A.; Gong, Z. Xmrk, kras and myc transgenic zebrafish liver cancer models share molecular signatures with subsets of human hepatocellular carcinoma. PLoS ONE 2014, 9, e91179. [CrossRef]

195. Chang, J.; Nicolas, E.; Marks, D.; Sander, C.; Lerro, A.; Buendia, M.A.; Xu, C.; Mason, W.S.; Moloshok, T.; Bort, R.; et al. miR-122, a mammalian liver-specific microRNA, is processed from hor mRNA and may downregulate the high affinity cationic amino acid transporter CAT-1. RNA Biol. 2004, 1, 106-113. [CrossRef]

196. Girard, M.; Jacquemin, E.; Munnich, A.; Lyonnet, S.; Henrion-Caude, A. miR-122, a paradigm for the role of microRNAs in the liver. J. Hepatol. 2008, 48, 648-656. [CrossRef]

197. Laudadio, I.; Manfroid, I.; Achouri, Y.; Schmidt, D.; Wilson, M.D.; Cordi, S.; Thorrez, L.; Knoops, L.; Jacquemin, P.; Schuit, F.; et al. A feedback loop between the liver-enriched transcription factor network and miR-122 controls hepatocyte differentiation. Gastroenterology 2012, 142, 119-129. [CrossRef]

198. Li, Y.W.; Chiang, K.Y.; Li, Y.H.; Wu, S.Y.; Liu, W.; Lin, C.R.; Wu, J.L. miR-145 mediates zebrafish hepatic outgrowth through progranulin A signaling. PLoS ONE 2017, 12, e0177887. [CrossRef]

199. Hand, N.J.; Master, Z.R.; Eauclaire, S.F.; Weinblatt, D.E.; Matthews, R.P.; Friedman, J.R. The microRNA-30 family is required for vertebrate hepatobiliary development. Gastroenterology 2009, 136, 1081-1090. [CrossRef]

200. Tonon, F.; Zennaro, C.; Dapas, B.; Carraro, M.; Mariotti, M.; Grassi, G. Rapid and cost-effective xenograft hepatocellular carcinoma model in Zebrafish for drug testing. Int. J. Pharm. 2016, 515, 583-591. [CrossRef]

201. Lin, H.S.; Huang, Y.L.; Wang, Y.S.; Hsiao, E.; Hsu, T.A.; Shiao, H.Y.; Jiaang, W.T.; Sampurna, B.P.; Lin, K.H.; $\mathrm{Wu}$, M.S.; et al. Identification of Novel Anti-Liver Cancer Small Molecules with Better Therapeutic Index than Sorafenib via Zebrafish Drug Screening Platform. Cancers 2019, 11, 739. [CrossRef] [PubMed]

202. De Oliveira, S.; Houseright, R.A.; Graves, A.L.; Golenberg, N.; Korte, B.G.; Miskolci, V.; Huttenlocher, A. Metformin modulates innate immune-mediated inflammation and early progression of NAFLD-associated hepatocellular carcinoma in zebrafish. J. Hepatol. 2019, 70, 710-721. [CrossRef] [PubMed]

203. Li, Y.; Li, H.; Spitsbergen, J.M.; Gong, Z. Males develop faster and more severe hepatocellular carcinoma than females in kras(V12) transgenic zebrafish. Sci. Rep. 2017, 7, e41280. [CrossRef] [PubMed] 
204. Chaturantabut, S.; Shwartz, A.; Evason, K.J.; Cox, A.G.; Labella, K.; Schepers, A.G.; Yang, S.; Acuna, M.; Houvras, Y.; Mancio-Silva, L.; et al. Estrogen Activation of G-Protein-Coupled Estrogen Receptor 1 Regulates Phosphoinositide 3-Kinase and mTOR Signaling to Promote Liver Growth in Zebrafish and Proliferation of Human Hepatocytes. Gastroenterology 2019, 156, 1788-1804. [CrossRef]

205. Nguyen, A.T.; Emelyanov, A.; Koh, C.H.; Spitsbergen, J.M.; Lam, S.H.; Mathavan, S.; Parinov, S.; Gong, Z. A high level of liver-specific expression of oncogenic Kras(V12) drives robust liver tumorigenesis in transgenic zebrafish. Dis. Models Mech. 2011, 4, 801-813. [CrossRef]

206. Nguyen, A.T.; Emelyanov, A.; Koh, C.H.; Spitsbergen, J.M.; Parinov, S.; Gong, Z. An inducible kras(V12) transgenic zebrafish model for liver tumorigenesis and chemical drug screening. Dis. Models Mech. 2012, 5, 63-72. [CrossRef]

207. Lu, J.W.; Yang, W.Y.; Tsai, S.M.; Lin, Y.M.; Chang, P.H.; Chen, J.R.; Wang, H.D.; Wu, J.L.; Jin, S.L.; Yuh, C.H. Liver-specific expressions of $\mathrm{HBx}$ and src in the p53 mutant trigger hepatocarcinogenesis in zebrafish. PLoS ONE 2013, 8, e76951. [CrossRef]

208. Rekha, R.D.; Amali, A.A.; Her, G.M.; Yeh, Y.H.; Gong, H.Y.; Hu, S.Y.; Lin, G.H.; Wu, J.L. Thioacetamide accelerates steatohepatitis, cirrhosis and HCC by expressing HCV core protein in transgenic zebrafish Danio rerio. Toxicology 2008, 243, 11-22. [CrossRef]

209. Kalasekar, S.M.; Kotiyal, S.; Conley, C.; Phan, C.; Young, A.; Evason, K.J. Heterogeneous beta-catenin activation is sufficient to cause hepatocellular carcinoma in zebrafish. Biol. Open 2019, 8. [CrossRef]

(C) 2019 by the authors. Licensee MDPI, Basel, Switzerland. This article is an open access article distributed under the terms and conditions of the Creative Commons Attribution (CC BY) license (http://creativecommons.org/licenses/by/4.0/). 